فاعلية برنامج إرشادي معرفي سلوكي في تنمية بعض مهار ات السلوك التكيفي للأطفال المعاقين حركيًّا

\title{
פ) ?)
}

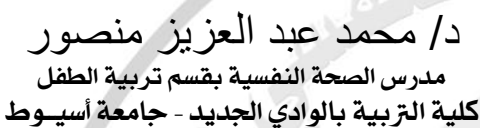

أ. د/ محمود إبر اهيم عبد العزيز أستاذ الصحة النفسية الساعد بقسم علم النفس

كلية الزبية بالوادي الجديد - جامعة أسيـوط

كلية التربية بالوادي الجديد - جامعة أسيـوط تربلفية

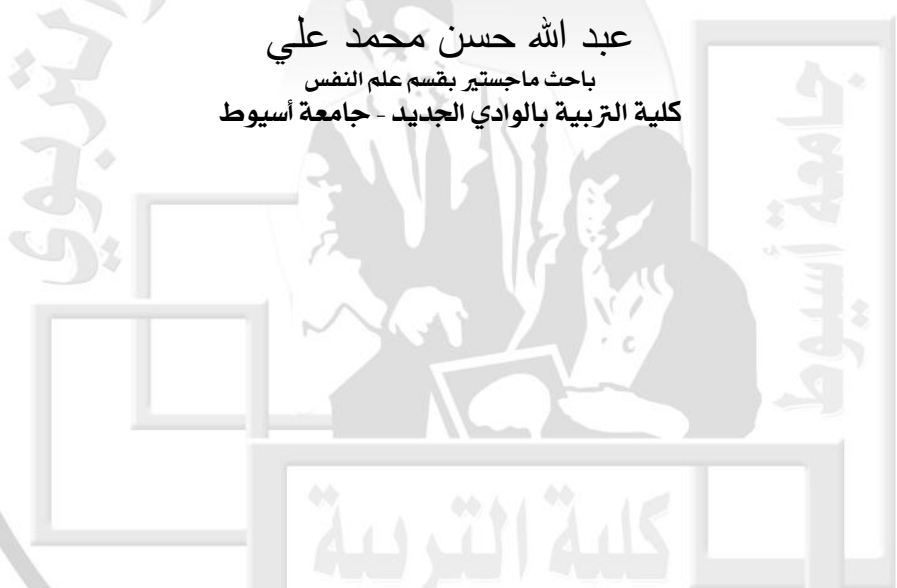

ومجتمعهم ومن ثم الوصول إلى الصحة

: Introduction مقدمة

النفسية .

لقد شهد مجال البحث العلمي خاصة في

واتجهت الدولة حديثًا في علوم ذوي السنوات الأخيرة تطورًا هائًا في البرامج الإعاقة والتأهيل وفي دراساتها التنربوية التي تتتاول ذوي الاحتياجات الخاصة والنفسية لنتاول فئات ذوي الإعاقات لتتمية مهاراتهم اللازمة لإتشباع حاجاتهم الخاصة بمختلف إعاقاتهم ، والدراسة

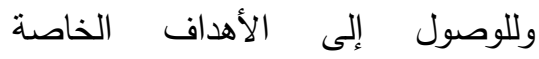
الحالية تتتاول فاعلية برنامج إرشادي الأساسية للتربية الخاصة من أجل التل معرفي سلوكي في تتمية بعض مهارات التوافق وتكيف السلوك مع ذئه ذواتهم السلوك التكيفي للأطفال المعاقين حركيًّا 
تحدد الكثير من الخصائص النفسية لشخصية المعاق وقدرته على التقاعل الاجتماعي السليم مع المجتمع لذلك فلا بد من التعامل مع الإعاقات الحركية بفاعلية عالية وطرق علمية مدروسة تعمل على مد يد العون للمعاق حركيًّا ليكون عنصرًا بناءً وشخصنًا قادرًا على ليى التعامل مع ذاته والآخرين من حوله (طارق عبد الرؤوف عامر وربيع عبد

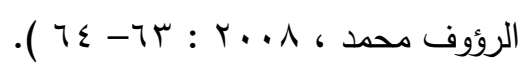

وللإزشاد المعرفي السلوكي تطبيقات عديدة أثتبت فاعليتها في : زيادة مستوى الاستقلالية وتحسين المهارات الأكاديمية ، تحسين المهارات السلوكية ، تعليم التفاعلات الاجتماعية ، فقد استخدم الإرشاد المعرفي السلوكي في تعليم المهارات للأطفال (إبراهيم عبداله

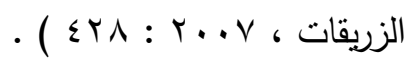

لذا فمن هنا إن الأطفال ذوبي الاحتياجات

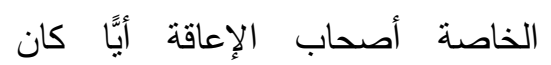
اختلاف إعاقتهم يحتاجون إلى أسلوب خاص للتعامل معهم ومناهج محددة لتربيتهم ومساعدتهم في ظهور مواهبهم وإبداعاتهم ، وتعد الإعاقة الحركية Physically Handicap تلك الإعاقات التي تحتاج إلى رعاية وإرشاد وتأهيل وتدريب لتتمية مهاراتهم
والملحقين بمدارس التعليم العام ؛ حيث أن بعضًا من أفراد المجتمع ينظرون إلى الطفل المعاق حركيًّا على أنه عاجز ولا ،يستطيع أن يقوم بأداء أعماله المستقلة ، وكذا نظرته السلبية لذاته التي أدت إلى لى لـ عدم إثباع حاجاته بسبب إعاقته التي تَحُول بينه وبين رفاقه في منل عمره ؛ ونتج عن ذلك العديد من المشكلات الحياتية الذاتية اللغوية والاجتماعية . وتعتبر الإعاقة الحركية أحد الإعاقات التي تؤثر على علاقة الفرد بالأشخاص المحيطين به وقد تصيب المعاق بسوء التوافق أكثز من أقرانه العاديين وتؤدي به إلى وجود العديد من المشكلات لديه مثل : السلوك الانسحابي ، الميول العدوانية ، ويتأثز سلوك نوافق المعاقين حركيًا باتجاهات المعلمين نحوهم سواء كانت اتجاهات الرفض أو الحماية الزائدة ؛ فالمعاق حركيًّا عادة ما يتأثز بطريقة تعامل الآخرين معه وطبيعة نظرته الخاصة إلى نفسه وتقييمه لقدراته وإمكانياته في التعامل مع المجتمع ومدى تقبله لإعاقته الحركية في المقام الأول وإن الحالة النفسية للمعاقين حركيًا نتأثز بالكثير من العوامل البيئية والتي بدورها 
نحو تحقيق توافقه الثخصي والاجتماعي والتمتع بصحة نفسية عالية قد تصل إلى حد السواء ، أما عن جانب القصور في مهارات السلوك التكيفي وضعف المهارات الاجتماعية وعدم تحقيق المعاق حركيًا للتكيف الاجتماعي وضعف في التعبير عن مشاعره وعدم التحكم في انفعالاته وسلوكياته كل هذا يؤدي إلى سوء تكيف مما ينعكس عليه في شتى مناحي الحياة

\section{مشكلة الدراسة :}

من خلال عمل الباحث في مجال التربية

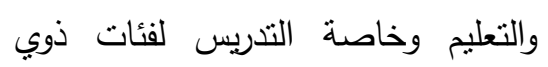
الإعاقة الحركية ، فاتجه انتباه الباحث إلى وجود مجموعة من المهارات التي

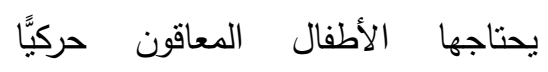
الملتحقون بمدارس التعليم العام •

وظهرت المشكلة من خلال المقابلة والزيارات المتكررة لأسر الأطفال ذوي الإعاقة الحركية واستمارة الملاحظة التي تم تطبيقها على هذه الفئة بأبعادها المختلفة ودرجاتها المتفاوتة ، ويتضح هذها من ذلك أن الأطفال المعاقين حركيًّا والملتحقين بمدارس التعليم العام لديهم بعض المشكلات التي يواجهونها في حياتهم العملية والعلمية ، وبذلك يمنلون

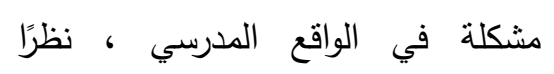

السلوكية التكيفية وللمساعدة في ظهور مواهبهم وإبداعاتهم لمهي

وفي الدراسة الحالية نسلط الضوء على الإعاقة الحركية كمشكلة في مجتمعنا من أجل العمل على توجيها وإرشادها ومعالجتها بطريقة مناسبة لنفسية المعاق ، ومن هنا جاءت فكرة الحاجة الضرورية إلى تصميم برنامج إرشادي معرفي سلوكي لتتمية بعض مهارات السلوك لك التكيفي للأطفال المعاقين حركيًا الملتحقين بالمدارس ؛ لإحداث توافق شخصي اجنماعي لديهم ، وذللك من خلال هذا البرنامج الذي يساعد على لى لئي

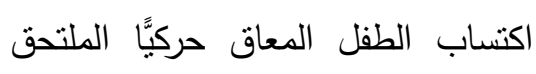
بالمدرسة بعض المهارات اللازمة التي

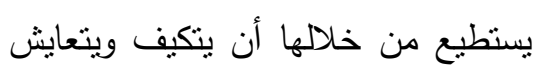
ويتوافق ويتفاعل مع بيئنه الطبيعية والاجتماعية ؛ ولعل تلاك الدراسة أن تشاعد الأطفال المعاقين حركيًّا الملتحقين بالمدارس على أن يؤدوا دورهم بحيث

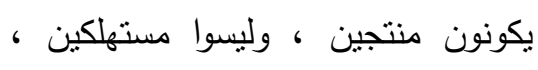
وحتى يستعيدوا ثقتهم بأنفسهم وتوافقهم الشخصي والاجتماعي من خلال تعزيز جوانب مهارات السلوك التكيفي وتعميقها في شخصياتهج ، لذا فنتمية جوانب مهارات السلوك التكيفي لذوي الإعاقة الحركية بمكن أن تمنل خطوة إيجابية 
حركيًا الملتحقين بالمدارس في العديد من مهارات السلوك التكيفي ، مما يستلزم وجود البرامج التأهيلية واليكي ، والإشادية والعلاجية والتدريبية المناسبة لتتمية هذه والإنية

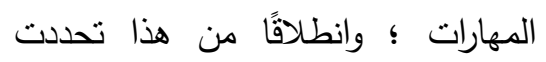
مشكلة الدراسة الحالية في التساؤلات التالية :

- ما فاعلية البرنامج الإرشادي المعرفي

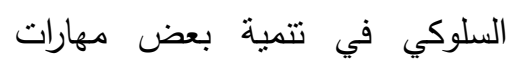
السلوك التكيفي للأطفال المعاقين تصنين

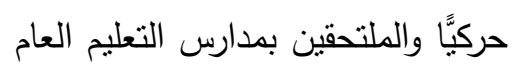

$$
\text { . }
$$

- هل البرنامج الإرشادي المعرفي

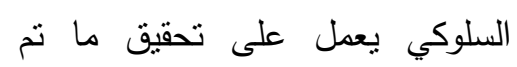
اكتسابه من تقدم في تلاك المهارات من

خلال القياسات التتبعية ؟

$$
\text { أهداف الاراسة : }
$$

تهدف الدراسة الحالية إلى :

1- التحقق من فاعلية البرنامج

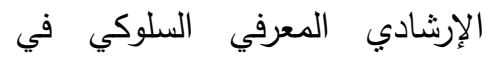
تتمية بعض مهارات السلوك التكيفي

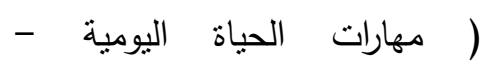
المهارات اللغوية - - المهارات الاجتماعية ) للأطفال المعاقين حركيًا والملتحقين بمدارس ل التعليم

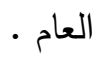

للعوامل الني أحاطت بهم وأدت إلى عدم إثباع حاجاتهم وعدم القدرة على التكيف الثا لهان والتوافق مع ذواتهم والمجتمع •

وبينت بعض الدراسات السابقة وجود مشكلات تتعلق بالإعاقة الحركية؛ فمنها:

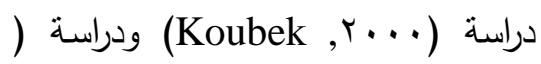

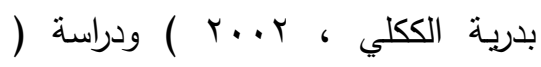

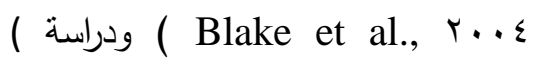
Sareen et al., , Y...0)

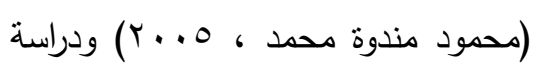

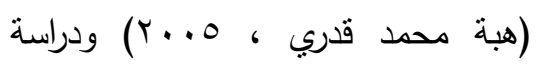

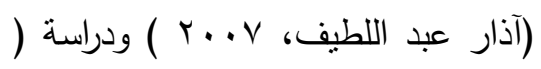
( Husain Zuhda et al , r.). حيث أكدت هذه الدراسات أن المعاقين

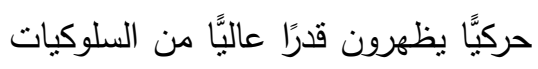

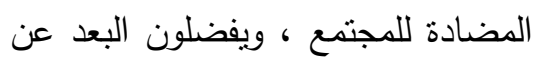

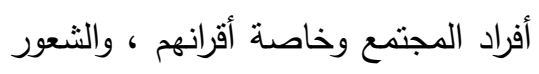

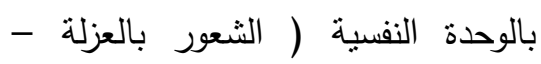
الحزن والتشاؤم ) ، وكذا نظرتهم السلبية

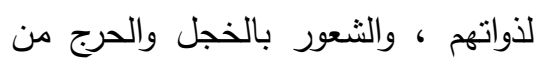
الآخرين ، وأن نسبة الضغوط النفسية

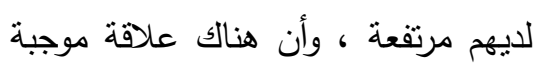

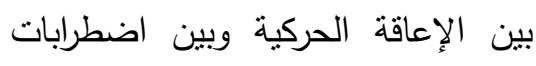
القلق ، ويفضلون الاعتماد على الآخرين

$$
\text { في إنباع حاجاتهم ، ونفرن الاتص }
$$

وبالتالي تتمثل مشكلة الدراسة الحالية في وجود قصور لدى الأطفال المعاقين 
الحياة اليومية والمهارات اللغوية

والمهارات الاجتماعية ".

ع - تسهم في دعم الإخصائيين

المتخصصين والمعلمين والآباء

وجميع المهتمين بشؤون الإعاقة

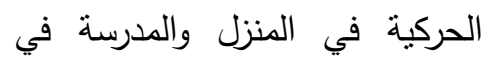

إعداد البرامج والنماذج الإرشادية

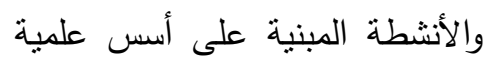

في تتمية مهارات السلوك التكيفي

لفئة الأطفال من ذوي الإعاقة

الحركية لحد من آثار الإعاقة .

0- تستقبد منها الأسرة في الوقوف

على احتياجات أبنائهم من ذوبي الأني

الإعاقة الحركية وحل مشكلاتهم

$$
\text { وتتمية بعض مهاراتهم الاعة وحكة }
$$

\section{مصطلحات الاراسة :}

1- - الإرشاد المعرفي السلوكي Behavioral

\section{Counseling}

Cognitive

تعرف الدراسة الحالية الإرشاد المعرفي السلوكي إجرائًًا على أنه : " " عملية تربوية تدريبية تستتد على دمج فنيات

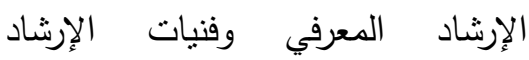
السلوكي معًا ، مما يؤدي إلى رفع قدرات الإندات الإندات الأطفال ذوي الإعاقة الحركية والملتحقين

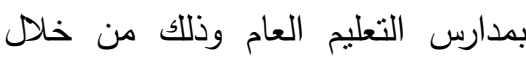

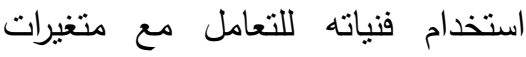
مهارات السلوك التكيفي وتقديم الخدمات
ץ- التعرف على مدى استمرارية أثز البرنامج الإرشادي المعرفي

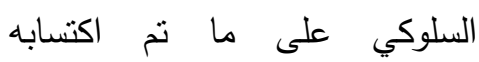
من مهارات السلوك التكيفي للأطفال

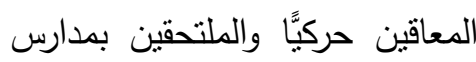
التعليم العام من خلال القياسات التتبعية .

\section{أهمية الدراسة :}

وتتحدد أهمية الدراسة الحالية في إنها: 1-تسهم في إثراء المكتبة العربية بمجموعة من الأدوات لم تقدم بعد

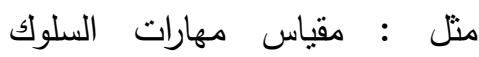
التكيفي ، واستمارة ملاحظة سلوك هلئ الطفل المعاق حركيًّا ، واستمارة

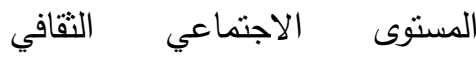
الاقتصادي.

r - نستمد أهميتها من أهمية المرحلة

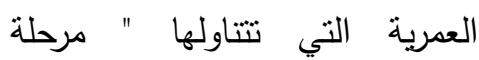
الطفولة " ، وما بصاحبها من لئل

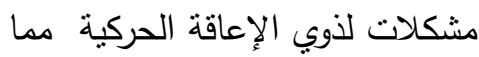
يتطلب الحاجة إلى برامج إرشادية وتأهيلية .

r - تقيد فئة الأطفال من ذوي الإعاقة الحركية والملتحقين بمدارس التعليم العام لتتمية بعض مهاراتهم السلوكية

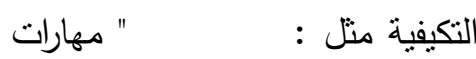


الوظيفية المستقلة لحياتهم اليومية والمسؤولية الثخية الثخية والاجتماعية

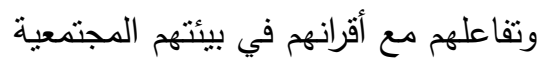

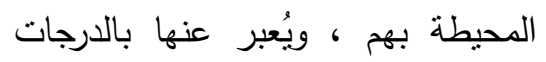

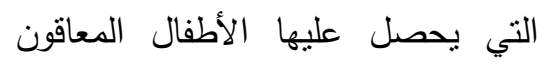

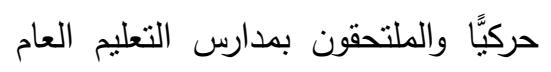
في مقياس مهارات السلوك التكيفي ولمئي

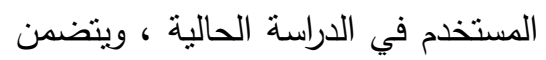

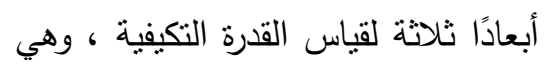

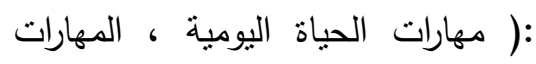

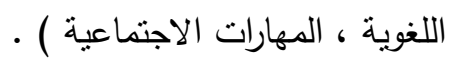

Physically الإعاقة الحركية

\section{: Handicap}

تثير الدراسة الحالية إلى الإعاقة الحركية على أنها : " اضطراب أو الوالية حالة من العجز في الوظائف الحركية ونقص في كفاءة الأطراف والعضلات

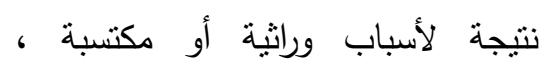

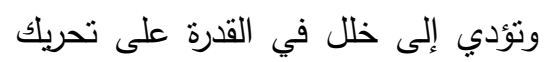
الجسم أو أحد أعضائه ، وهذه الإعاقة

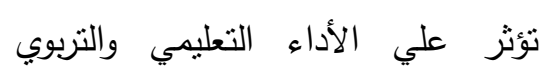
والاجتماعي للشخص المعاق ؛ ومن ثم ثن

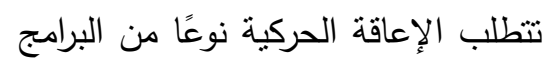
التربوية والتأهيلية والعلاجية والإرشادية . المنهج المستخدم وأدوات الدراسة
الإرشادية والعلاجية ومساعدتهم على

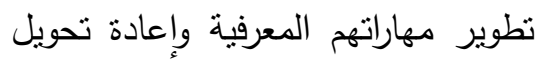
أفكارهم السلبية إلى إيجابية ، وممارسة المبرة السلوكيات الصحيحة وتدعيمها ".

(البرنامج الإرشادي المعرفي السلوكي The Cognitive Behavioral Counseling : Program

تعرفه الاراسة الحالية إجرائيًا بأنه : "

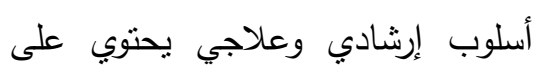

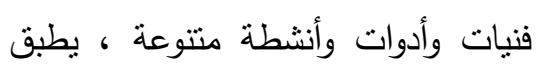

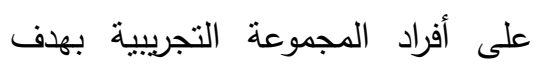
تتمية مهارات السلوك التكيفي لأطفال

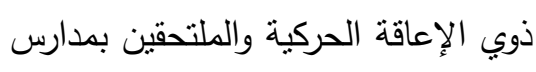
التعليم العام ، مما بسهم في تحقيق وليق

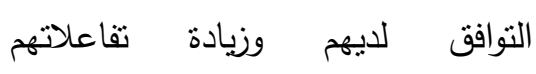
الاجتماعية وتواصلهم مع الآخرين وزيادة تقتهم بأنفسهم في المسؤوليات والأعمال

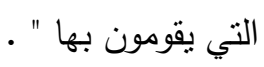
r) مهارات السلوك التكيفي Adaptive $\quad$ Skills

تعرف مهارات السلوك التكيفي في التئي الدراسة الحالية إجرائيًا بأنها : " " قدرة لأيفي

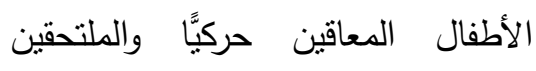

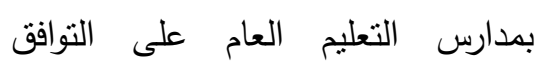
الشخصي والاجتماعي وإثباع حاجاتهم من أجل تحقيق المهارات الأدائية 
r) حصر وجمع كل ملفات أطفال ذوي الإعاقة الحركية المسجلين بمدارس التعليم الأساسي بالخارجة

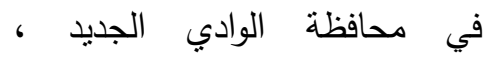
واستكمال النواقص من المعلومات.

؛) تصميم اختبارات ومقاييس تحنوي على عدة استمارات لتجميع معلومات ( طبية - حيانية - لغوية - انفعالية - نفسية -اجتماعية - نقافية وتعليمية - اقتصادية - جغرافية ) وتصنيف الإعاقات الحركية وتسجيلها. 0) تصميم مخطط لجلسات البرنامج الإرشادي المعرفي السلوكي •

7) تم تحكيم الأدوات المصممة لتحقيق أهداف الدراسة الميدانية . تحكمات الادية

V الطبيق أدوات الدراسة على العينة الاستطلاعية لحساب الصدق والثبات من خلال البرنامج الإحصائي .(SPSS)

^) إدخال بيانات العينة للأدوات

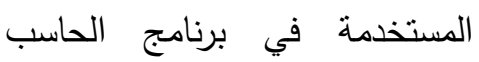
الآلي للمعالجة الإحصائية.

9) تحديد مواصفات عينة الدراسة والالتزام بها . • (1) تطبيق جلسات البرنامج الإرشادي المعرفي السلوكي واستمارة نقييمه الإنداديا على العينة التجريبية .
المنهج المستخدم : المنهج شبه التجريبي ذو المجموعة الواحدة في الدراسة التجريبية. أدوات الدراسة :

- استمارة ملاحظة سلوك الطفل

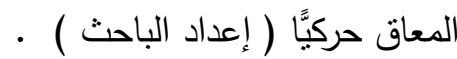
- - استمارة المستوى الاجتماعي التقافي الاقتصادي(إعداد الباحث ). - مقياس مهارات السلوك التكيفي

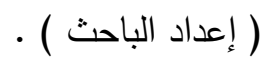
- - - جلسات البرنامج الإرشادي المعرفي السلوكي (إعداد الباحث) .

\section{إجراءات الدراسة الميدانية :}

يشير الباحث إلى أن الخطوات الإجرائية التي اتبعت في الدراسة الميدانية الحالية

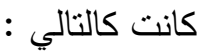

(1) الاطلاع على الأبحاث العلمية

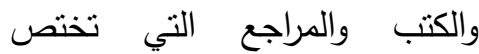
بمهارات السلوك التكيفي وذوات التوبي الإعاقات الحركية والبرامج الإرشادية للاستفادة منها في الدراسة الحالية . T) تتكيل فريق مساعد متعدد

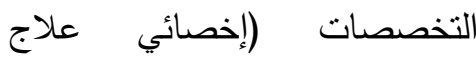
طبيعي أو معلم تربية رياضية - إخصائ إخصائي اجنماعي / نفسي- مدير مدرسة - مبرمج حاسب آلي إئي ) . 
- ميتمنل مجتمع الدراسة من مجموعة من نلاميذ مدارس مرحلة التعليم الأساسي بمحافظة الوادى الجديد بمدينة الخارجة وتحديدًا التلاميذ المعاقين حركيًا .

الدراسة الميدانية وتثضمن :

\section{أ ) عينة الدراسة الاستطلاعية :}

تمثلت عينة الدراسة الاستطلاعية من تلاميذ مدارس مرحلة التعليم الأساسي بمدينة الخارجة بمحافظة الوادي الجديد، وتم اختيارهم بطريقة عشوائية بسيطة ، وبلغ عددهم خمسة وتسعون تلميذًا وتلميذة ، وتم تطبيق أدوات الدراسة عليهر لتأكد من صدق وثبات المقاييس المستخدمة في الدراسة الحالية ؛ وعدد أفراد العينة الاستطلاعية يوضحه جدول ( ) (1) (لتالي (2)
(1) تحليل النتائج من خلال البرنامج الإحصائي ( SPSS )

r (ا) الاستتاجات وتفسير فروض الدراسة الحالية في ضوء الإطار النظري والدراسات السابقة.

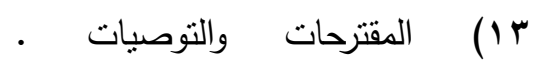

\section{منهج الدراسة والعينة :}

- للإجابة عن تساؤلات الدراسة ، اتبع الباحث : المنهج شبه التجريبي، باستخدام تصميم المجموعة الواحدة ذات القياس القبلي والبعدي ، وذللك لكان لإثبات فروض معينة تمهيدًا

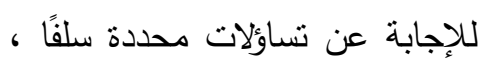
وبعد تدخل من الباحث في مجرياتها

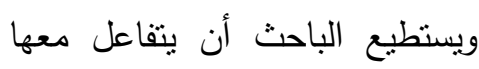
بشكل علمي وموضوعي ؛ واستخدام المقارنة وذللك للوقوف على أهم • الفروق

\section{جدول (1)}


عدد أفراد العينة الاستطلاعية في الدراسة الحالية

\begin{tabular}{|c|c|c|c|c|}
\hline \multicolumn{3}{|c|}{ 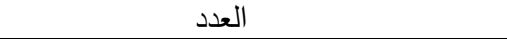 } & \multirow{2}{*}{ اسم المدرسة } & \multirow[b]{2}{*}{5} \\
\hline الجملة & إناث & ذكور & & \\
\hline$r T$ & 10 & 11 & أبو بكر الصديق الابتدائية & 1 \\
\hline 1 & - & 1 & السبط البحري الابتدائية & r \\
\hline rt & 17 & 7 & السلام الابتدائية القديمة & $r$ \\
\hline 1 & 1 & - & المروة الابتدائية & $\varepsilon$ \\
\hline ir & $\varepsilon$ & $\Lambda$ & المروة الإعدادية & 0 \\
\hline 1 & - & 1 & 7 أكتوبر الابتدائية & 7 \\
\hline 1 & 1 & - & صلاح الدين الابتدائية & $\mathrm{V}$ \\
\hline ro & 10 & 1. & عبد المجيد الجغيل الابتدائية & $\wedge$ \\
\hline$r$ & 1 & 1 & عمر بن الخطاب الابتدائية & 9 \\
\hline$\varepsilon$ & r & $r$ & عين الدار الابتدائية & 1. \\
\hline 90 & 00 & $\varepsilon$. & مــوع & 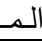 \\
\hline
\end{tabular}

المعاقين حركيًا ونم اختيارهم بالطريقة ب ) عينة الدراسة التجريبية :

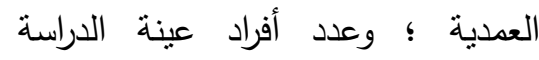
التجريبية يوضحه جدول (r) التالي : العديه

تكونت عينة الدراسة التجريبية من سبعة تلاميذ يمنلون التلاميذ

جلول (r)

عدد أفراد العينة التجريبية في الدراسة الحالية

\begin{tabular}{|c|c|c|c|}
\hline 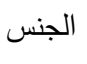 & 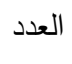 & الم الدرسة & 5 \\
\hline ذكر & $r$ & أبو بكر الصديق الابتنائية & 1 \\
\hline ذكر & 1 & السبط البحري الابتدائية & r \\
\hline ذكر & 1 & ד أكتوبر الابتدائية & $r$ \\
\hline ل & 1 & الخارجة الابتدائية المشتركة & $\varepsilon$ \\
\hline ذكر & 1 & المروة الإعدادية & 0 \\
\hline \multicolumn{2}{|c|}{ V ذكور } & \multicolumn{2}{|c|}{ 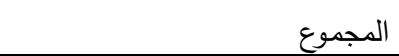 } \\
\hline
\end{tabular}

- تقرير طبي من جهة حكومية أو

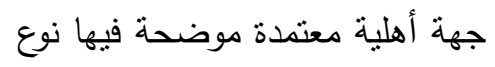
الإعاقة الحركية . لهنه معندة - قبول المراحل العمرية للتلاميذ ذوي الإعاقة الحركية الذين نتزاوح أعمارهم بين سن (^ - ع الاعة سنة ).
وتم تحديد مواصفات العينة التجرييية للاراسة الحالية وفقًا للمواصفات التالية: - إثبات شخصية التلميذ المعاق حركيًا والتأكد من معلومات شخصيته ومطابقتها . 
أدوات الدراسة :

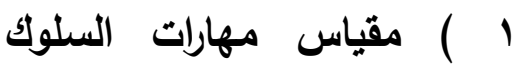

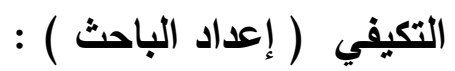

( أ ) وصف المقياس : يتكون مقياس

مهارات السلوك التكيفي من ستين

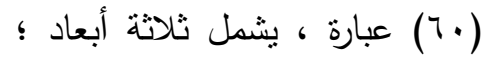

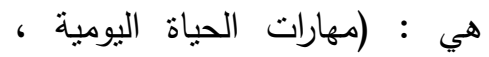

والمهارات اللغوية ، والمهارات الاجتماعية) ، ويوضح عبارات كل الفراته

بعد من أبعاد المقياس جدول وبوضح عبارات (r)
- أن يكون التلاميذ من ذوي الإعاقة الحركية البسيطة .

الحركية في الفصل الدراسي العادي الفي طيلة الوقت . - فحص نفسي يحدد مسنوى القدرة العقلية ودرجة الذكاء .

- أن يكون التلاميذ ذوو الإعاقة الحركية ممن يتراوح مستوى ذكائهم لإنها كمنل التلاميذ العاديين. - بحث اجتماعي عن المعاق حركيًا وأسرته ، يظهر الجوانب الاقتصادية والتعليمية والثقافية والجغرافية .

\section{جلول ( ) - )}

يوضح عبارات كل بعد من أبعاد مقياس مهارات السلوك التكيفي في الاراسة الحالية

\begin{tabular}{|c|c|c|c|}
\hline أرقام العبارات & أرقام العبارات & الأبعاد & e \\
\hline$Y r-17-\varepsilon$ & $\begin{array}{l}-19-19-1 r-1 \cdot-V-\varepsilon-1 \\
-r V-r \varepsilon-r 1-r 1-r 0-r r \\
-00-0 r-\varepsilon q-\varepsilon r-\varepsilon r-\varepsilon . \\
\end{array}$ & مهارات الحياة اليومية & \\
\hline 07 & 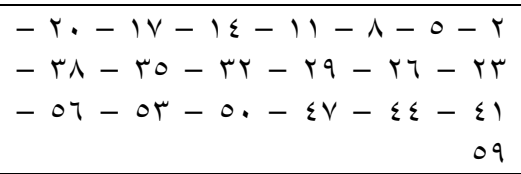 & المهارات اللغوية & r \\
\hline 1 & 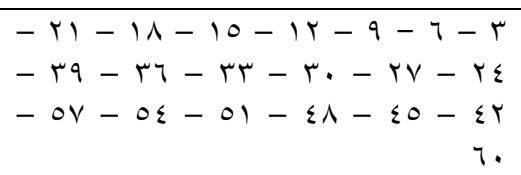 & الدهارات الاجتماعية & r \\
\hline
\end{tabular}

ليكرت للنقاط ( r نقاط ) والذي يتراوح (ب) تصحيح المقياس : يحتوي المقياس

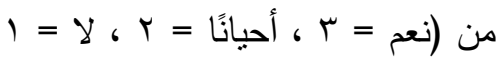

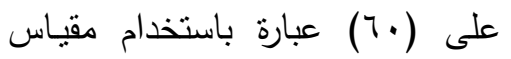


من أجله ، ومناسبة سلم التقدير للإجابة ، إضافة إلى مدى وضوح ، ونأنه صياغة كل عبارة ، وإمكانية تعديل الصياغة أو حذف أو إضافة عبارات جديدة ، ليصبح المقياس أكثر قدرة على تحقيق الهدف الذي جارت الذيات بني من أجله ، وهذا ما يعبر عن

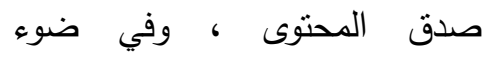

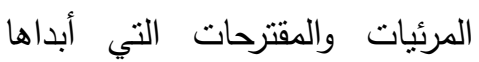
السادة المحكمون تم اجراء التعديلات ، وتم عرض المقياس على عشرين

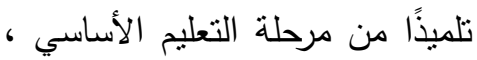

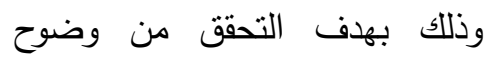
التعليمات والعبارات والتعرف على ونى الدقة في صياغتها ، حيث تم إعادة صياغة العبارات غير الواضحة لهم

- - استقر الرأي على العبارات التي حصلت على اتفاق المحكمين

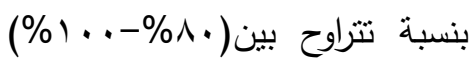

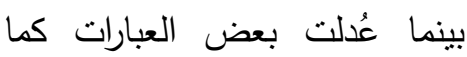

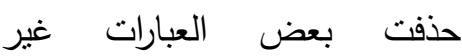
المناسبة وبذلك يكون المقياس من بعضي سنين ( • . ) عبارة . - صدق المحك : وذلك عن طريق حساب معامل ارتباط بيرسون بين

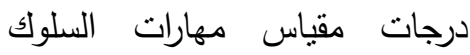

) يجيب التلاميذ حسب معدل تكرار حدوث السلوكيات بالنسبة لهم وما تتطبق عليهم الاستجابة مبينة الاعتقادات بوضوح ، وفقًا لما ذكره الباحث ، وتراوحت الدرجة المعيارية

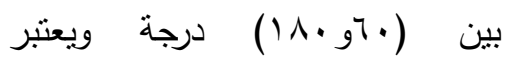
المتوسط الثامل لـقياس مهارات السلوك التكيفي هو (•r ال) درجة .

الخصائص السيكومترية لمقياس مهارات السلوك التكيفي (الصدق والثبات) : للتحقق من ثبات وصدق المقياس بأبعاده

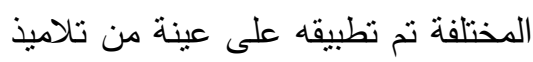

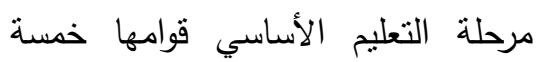

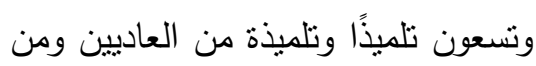
ذوي الإعاقة الحركية وتم اختيارهم بطريقة عشوائية من مدارس مختلفة .

\section{أولًا صدق المقياس :}

- صدق المحكمين : تم عرض الاختبار في صورته الأولية على لثى

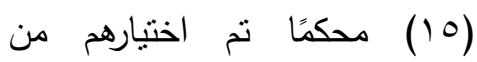
الخبراء المتخصصين في مجال التمال الصحة النفسية والإرشاد النفسي

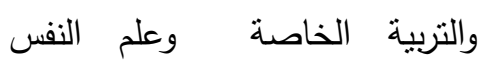
التربوي بالجامعات المصرية ، وذلك بهدف إبداء آرائهم في صلاحية وشمولية العبارات لقياس ما وضعت 
مهارات الحياة اليومية ، المهارات اللغوية ، المهارات الاجتماعية )

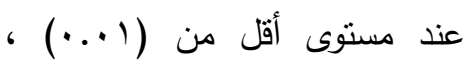

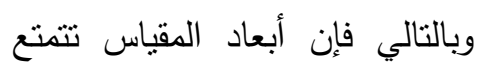
بالقدرة على التمييز بين المستوبين

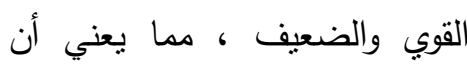
المقياس يتمتع بدرجة عالية من ولن لمنيف ان الصدق . - مان

- - صدق الاتساق الداخلي : نم

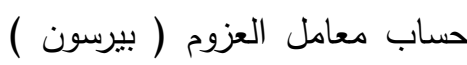
بين كل بند من بنود المقياس والدرجة الكلية للبعد الذي تنتمي إليه وبين درجة كل بعد والدرجة الكلية

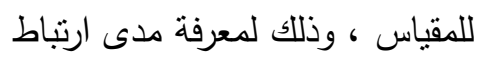

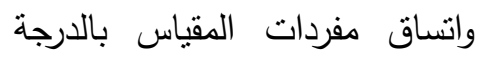

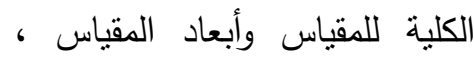
واتضح أن بنود مقياس مهارات

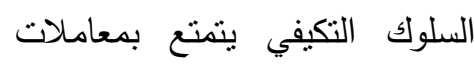

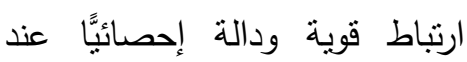
مستوى (1 (ل..) مع الدرجة الكلية

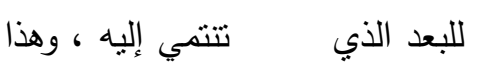
بدل على أن المقياس بدفرداته يتمتع باتساق داخلي عالي.

\section{ثانيًا ثبات المقياس :}

Alpha الثبات بطريقة ألفا-كرونباخ : تم حساب قيمة معامل ألفا كرونباخ وتبين أن معاملات الثبات

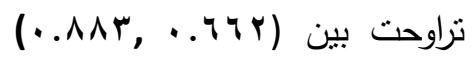

التكيفي ودرجات مقياس السلوك

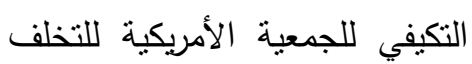

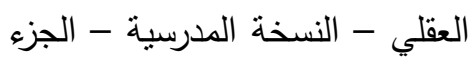
الأول (ب99 199 م) : نرجمة وتقنين

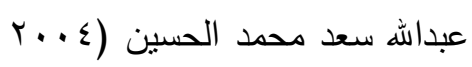
م) ، حيث إن : معامل الارتباط بين بعد الوظائف الاستقلالية

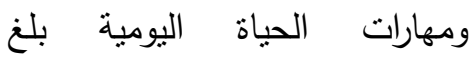
(النع بعد النمو اللغوي والمهارات اللغوية ، ومعلمالإنية

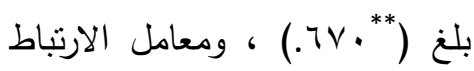
بين بعد المهارات الاجتماعية

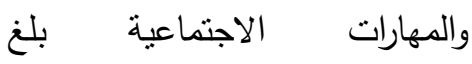

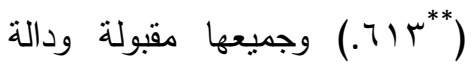
إحصائيًا عند مستوى دلالة (1. (... - - صدق المقارنة الطرفية : قام الباحث بترتيب درجات عينة التقنين ترتيبًا تتازليًا في كل بعد من بعدي درجات المقياس وكذلك الدرجة الكلية TV للمقياس، وتم تقسيم الدرجات \% علوي و \% F سفلي، ثم بعد ذلك

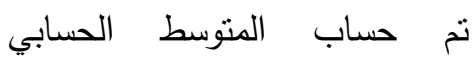
والانحراف المعياري للمستويين العلوي والسفلي ثم حساب قيمة " ت T-Test " والسفلي ، واتضح وجود فروق ذات دلالة إحصائية في كل بلفح وجدون فروث دات 
تراوح معامل جيتمان لدرجات المقياس

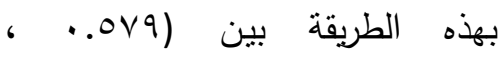
.10..) وجميعها قيم درتفعة من

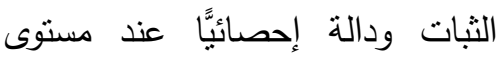
دلالة (1 (..) ، وبعد تطبيق معادلة سبيرمان براون تراوح معامل الثبات بين (1097. ، ، ، . . ) وجميعها قيم مرتفعة من الثبات ودالة إحصائيًا عند مستوى دلالة (1 (. . ) ، ويعد هذا دليلًا كافيًا على أن مقياس مهارات السلوك التكيفي بتمتع بدرجة ثبات

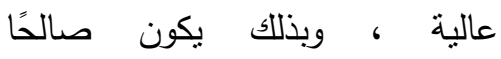
ل لاستخدام
وجميعها قيم مرتفعة من الثبات ودالة إحصائيًا عند مستوى دلالة (1 (. . . ) مما يعني أن أبعاد مقياس مهارات

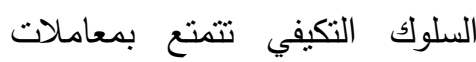
ثبات عالية ، وبذلك يكون صالحًا •لاستخدام

- - الثبات بطريقة التجزئة النصفية Split-Half Method معاملات الثبات باستخدام طريقة التجزئة النصفية ، حيث تم تقيم بنود المقياس إلى نصفين، ومن ثم حساب معامل الارتباط بين مجموع فقرات النصف الأول ومجموع فقرات النصف الثاني للمقياس ، حيث بلغ

جدول (๕)

جلسات البرنامج الإرشادي المعرفي السلوكي

\begin{tabular}{|c|c|c|}
\hline موضوع الجلسة & عنوان الجلسة & 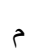 \\
\hline 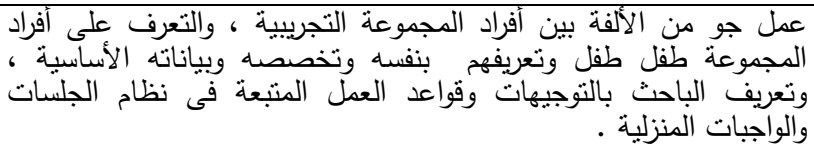 & تمهيد وتعارف & 1 \\
\hline 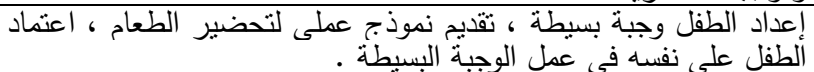 & مهارة تحضبر & r \\
\hline 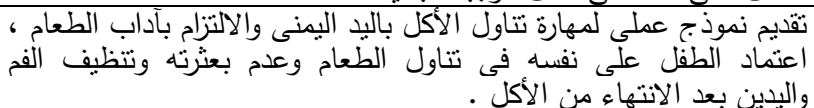 & مهارة تناول الطعام & r \\
\hline توجيه نظر وفرشاة لنظافة الطي أهمية تنظيف الأسنان وتتمية قدرته على استعمال & 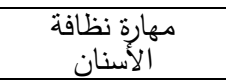 & $\varepsilon$ \\
\hline تعن ظهره الطفل على ارتداء وخلع الملابس بنفسه ، التمبيز بين وجه القميص & مهارة ارتذاء وخلع & 0 \\
\hline تقديم نموذج عملى عملى لمهارة تهذيب الشعر باستخدام الفرشاة والمشط بطريقة & مهارة تهذيب الشعر & 7 \\
\hline
\end{tabular}

\section{تابع جدول (؛ )}

جلسات البرنامج الإرشادي المعرفي السلوكي 


\begin{tabular}{|c|c|c|}
\hline موع الجلسة & عنوان الجلسة & r \\
\hline 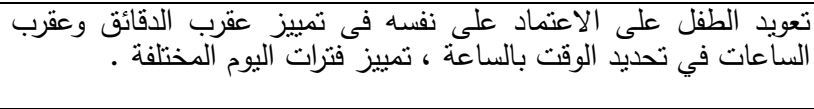 & الزهارة تحديد خلاملة & $V$ \\
\hline 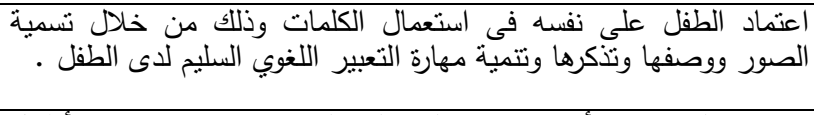 & مهارة التعبير عن & $\wedge$ \\
\hline 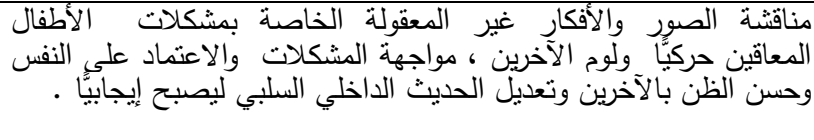 & والأفكار تحديد المعقولة & 9 \\
\hline 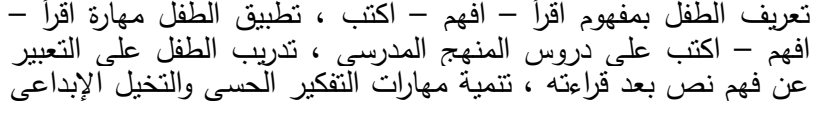 & اكتب اقرأ - افهم - & 1. \\
\hline 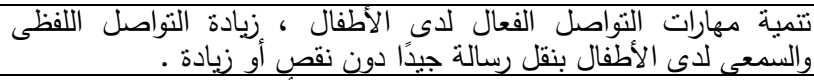 & اللغوي & 11 \\
\hline 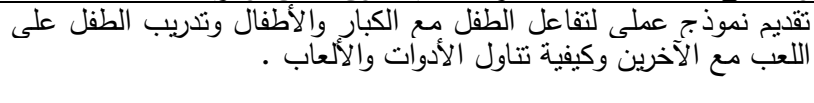 & الآجنماعى & IT \\
\hline 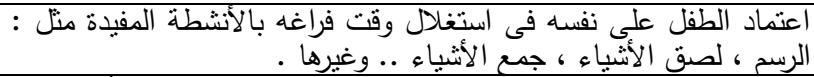 & الفرارة آنشطة وقت & $\pi$ \\
\hline 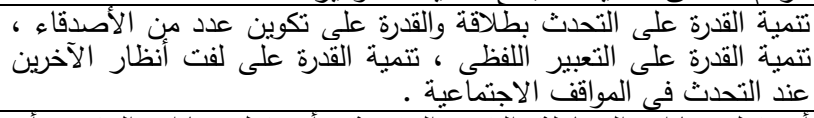 & 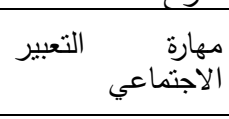 & $1 \leqslant$ \\
\hline 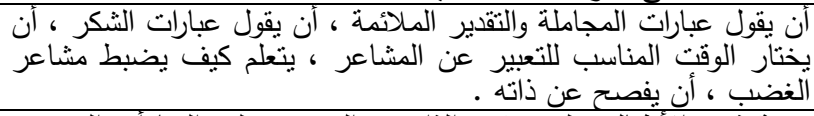 & 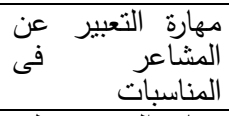 & 10 \\
\hline 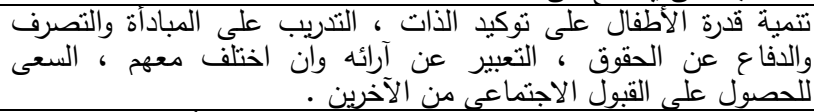 & المهارة التندريب على النيدي & 17 \\
\hline 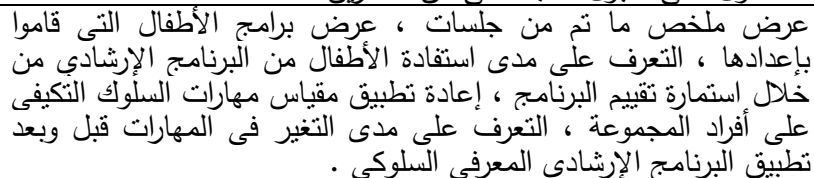 & البرنامجة وتقيبم آثار & $1 \mathrm{~V}$ \\
\hline
\end{tabular}

ويتتاول الباحث نتائج التحليل

الإحصائي لاختبار فروض الدراسة

وتقسيرها ومناقثتها في ضوء الإطار

النظري ونتائج الدراسات السابقة وفقًا

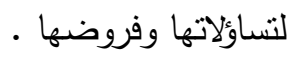

ولاختبار فروض الدراسة تم استخدام التحليل الإحصائي لبرنامج الرزم الإحصائية للعلوم الاجتماعية (SPSS) 9 - تفسير نتائج الدراسة : بتتاول الباحث تحليل نتائج الدراسة واختبار فرضياتها لمعرفة مدى تحقق أهداف الدراسة التي تنتئل في : (فاعلية برنامج إرشادي معرفي سلوكي في تتمية بعض مهارات السلوك التكيفي ل لأطفال المعاقين حركيًّا) . عن طريق استخدام الأساليب الإحصائية 
اختبار ويلككسون (Wilcoxon ) Signed Ranks Test لابارامتري بستخدم لمعرفة دلالة الفروق

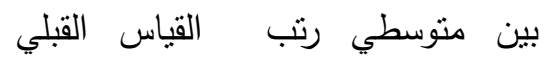
والبعدي (عند صغر حجم العينة) أب دئ لئي

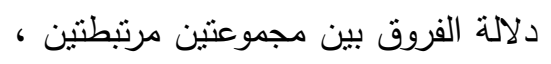

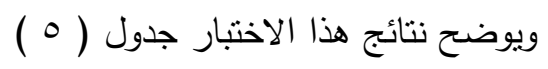

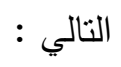

التالية : (المتوسطات الحسابية الانحرافات المعيارية ، اختبار ويلككسون

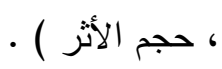

وللتحقى من الفرض الأول والذي ينص

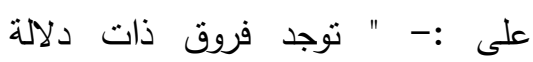
إحصائية بين منوسطي رتب القياس القبلي والبعدي لمقياس مهارات السلوك دئك

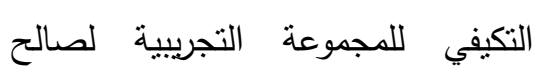

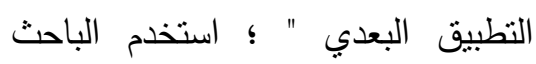

\section{) جدول( )}

يبين قيمة (Z) لدلالة الفروق بين متوسط رتب درجات أفراد المجموعة التجريبية في

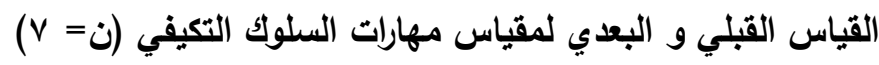

\begin{tabular}{|c|c|c|c|c|c|c|c|}
\hline الأثّز & الدلالة & قيمة (Z) & مجموع & مترتب & العدد & المجموعة & المتغير \\
\hline .199 & \multirow{4}{*}{$\ldots 0$} & \multirow{4}{*}{ T.M74 } & $\cdots$ & $\cdots$ &. & الرتب السالبة & \multirow{4}{*}{ 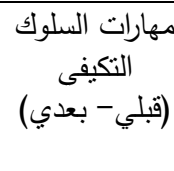 } \\
\hline & & & $r \wedge . .$. & $\varepsilon \ldots$ & $\mathrm{v}$ & الرتب الموجبة & \\
\hline \multirow[t]{2}{*}{ مرتفع } & & & & & $\dot{ }$ & الرتب المحايدة & \\
\hline & & & & & $\mathrm{v}$ & المجموع & \\
\hline
\end{tabular}

مهارات السلوك التكيفي للمجموعة

التجريبية لصالح التطبيق البعدي " .

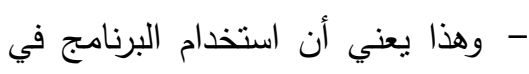

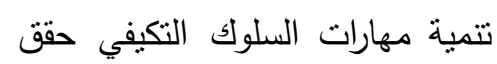

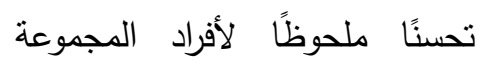

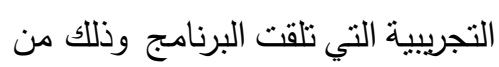
حيث اكتساب المهارات التي تعد مهمة

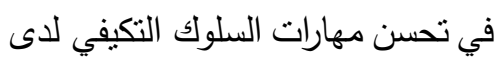
الأطفال المعاقين حركيًا والملتحقين بمدارس التعليم العام .
يتضح من الجدول (0) السابق أن قيمة

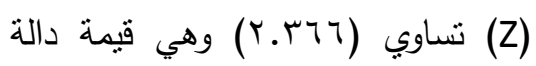

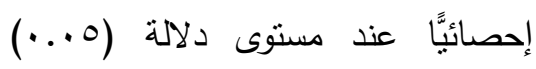
وهذا يعني أنه " توجد فروق ذات دلالة إحصائية بين متوسطات درجات أفراد المجموعة التجريبية في القياس القبلي دروسي

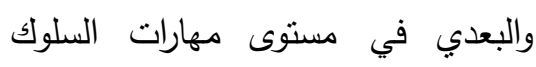
التكيفي لصالح القياس البعدي " . . - أوضحت النتائج أنه "توجد فروق

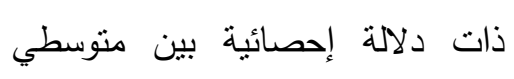
رتب القياس القبلي والبعدي لكقياس دلاس لئنس 
Paskiewicz

r.. 9 )

و (سهير سلامة ، 10 . ب ) ) وتمثلت

$$
\text { في الآتي : العيز }
$$

1- العوامل الاتئ المتعلة بالطقل :

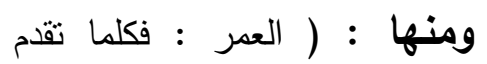

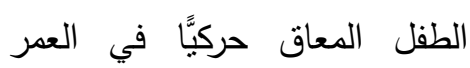

يكون أكثر نضجًا وتكيفًا ، أي كلما

زاد عمر الطفل زادت المهارات

التكيفية ؛ الجنس : حيث أن الذكور

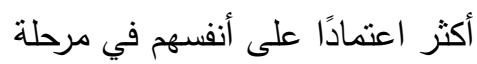

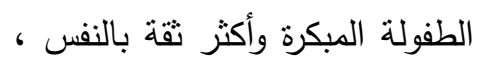

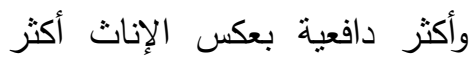

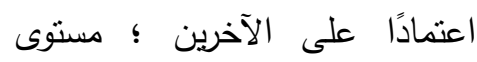

الذكاء : الذكاء يؤثر بنسبة .0 \%

على سلوك الطفل المعاق حركيًا

حيث ترتبط مهارات السلوك التكيفي

بمعاملات الذكاء IQ التي تقاس

بواسطة مقارنة قدرات الطفل مع أطعاء الخعات

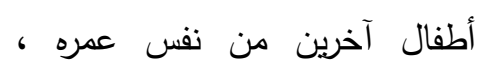
وخاصة مجال التواصل ) من لفرن

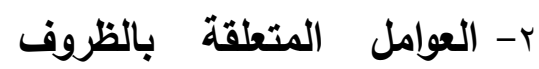

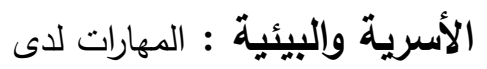

الأطفال المعاقين حركيًا تتمو بشكل تدريجي تنبأ من الولادة وتتأثز بعوامل عدة حسب البيئة أو الأفراد الذين يتعاملون معهم أو المؤسسات التي يتلقى فيها مبادئ النشء والقيم وينمو السلوك المهاري المستقل
- ماتققت الدراسة الحالية مع دراسة كلٍ

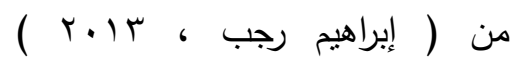

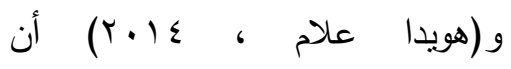
خصائص مهارات السلوك التكيفي تبدو فيما يلي : فهي أحد الدحكات

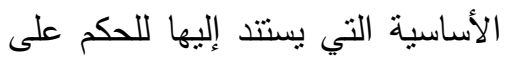
وجود الإعاقة ، وتتأثر بالظروف لإني

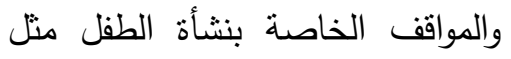
مركزه في الأسرة أو ترتيبه بين أخواته ... . . . وتتأثر بالمجموعة العمرية

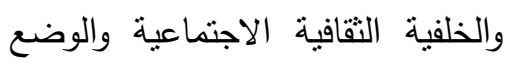
المجتمعي ، وتزّداد تعقيدًا بازدياد العمر الزمني ، وتعتبر مهارات سلوكية أدائية بنَّاءة وهادفة تُكُنّاه من من النتوافق مع بيئته بطريقة صحيحة وفعالة ) . مأن

- وأكدت الدراسة الحالية أن هناك

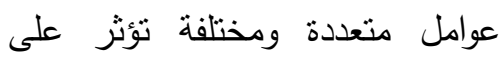
الأطفال ذوي الإعاقة الحركية منذ تونية

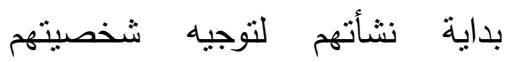

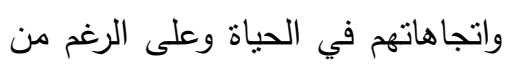

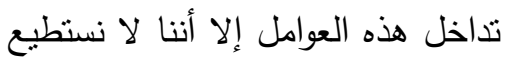
أن نختلف على أن هناك عألى عوامل رئيسة تؤثر على الطفل المعاق حركيًا وعلى تتمية هذه المهارات ، واتفق في دئي

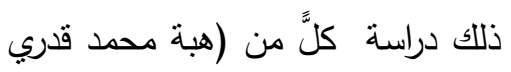

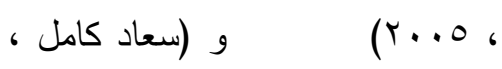
19 (r... 
الزائدة - ورفض الإعاقة، فالوالدان

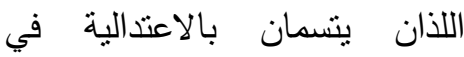

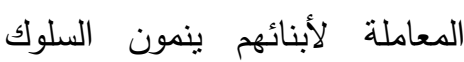

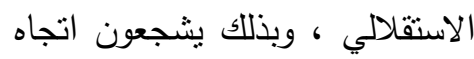

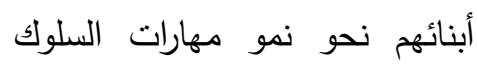

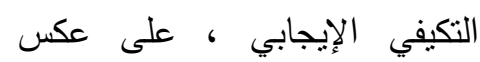
الوالدين اللذين يتسمان بالرفض على الإبي • لأبنائهر

r) البيئة المنزلية : الطهائة الطفل المعاق حركيًا الذي بنشأ في أسرة بتمبز جوها بالدفء والحب والرعاية تتمو لألئ

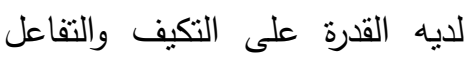

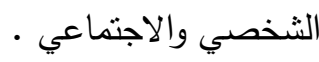
r) حجم الأسرة : فالأسرة كبيرة العدد تقلل من الرعاية التي ينالها أبناؤها،

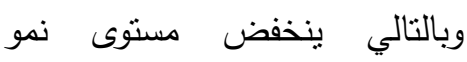

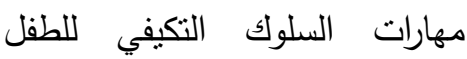
المعاق حركيًا بعكس الأسرة قليلة العدد ، وأثثت الأبحاث أن العائلات العكات

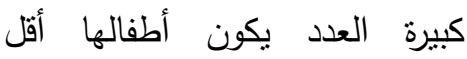

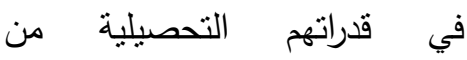
العائلات الصغيرة لاتهن

§) المستوى الثقافي للأسرة : فالأسرة

التي تتميز بمستوى ثقافي مرتفع ، تسهم بدورها في رفع مستوى قدرات

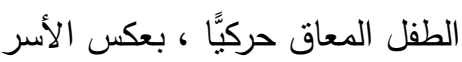

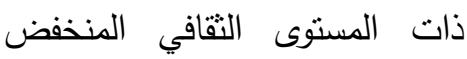
تعرض طفلها للإحباط والفشل والعجز عن مواجهة المواقف . لاحساط
بالنضج والتعلم ، حيث إن الأسرة

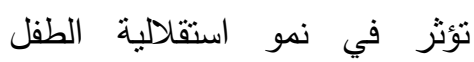

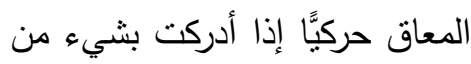

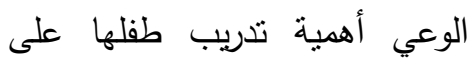

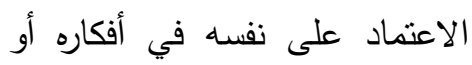
أفعاله حتى لاعئماد على نلهول لشخص اعتمادي ، ويجب نعويد الطفل على لئل

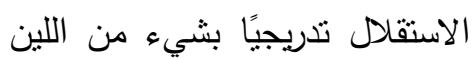
يتتاسب مع سنه وقدراته وليس باستخدام القسوة أو بالحماية الزائدة

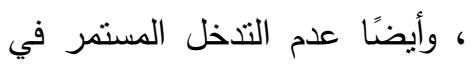
كل شيء يخص الطفل بل يجب

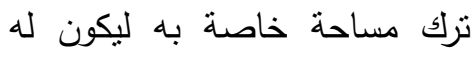
أفكاره أو لعبه الخاصة بدون تدخل الأسرة ، وكذلك يجب توجيه الآباء

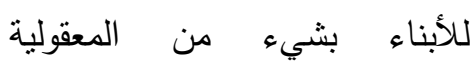
وباستخدام أسلوب المناقثة والإقناع ، وعدم حرمان الطفل من متعة العبث بالأشياء والتعرف على كلى له ما يقع تحت يديه وخاصة إذا كان يعاني من إعاقة جسدية مثل : " لماني شلل الأطفال"؛ لننمي بداخله نقته بنفسه وإحساسه بقيمة ذاته ؛ ونلخص هذه العوامل فيما يلي :

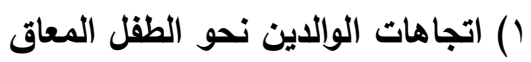

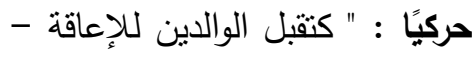
والاستجابة الإنكارية - والحماية لإعاية 
الإعاقة الحركية على المستوى

الاقتصادي من حيث ضعف قدرته

وكفاءته الإنتاجية في عمله .

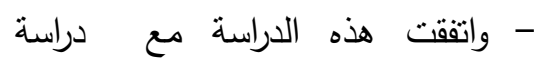

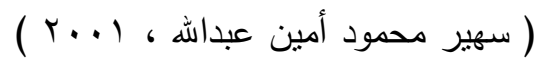

ودراسة ( Harris, et al, r...r )

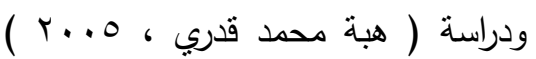

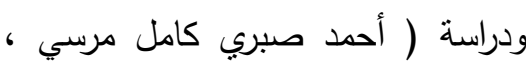
r Y. T ) في بناء استراتيجيات ملائمة

للأطفال المعاقين حركيًا لتتمية قدراتهم

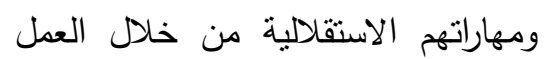
الحر للاعتماد على أنفسهم مع ضرورة تقديم المعززات على نجاحهم في الأداء باستقلالية ، وأنه كلما تقدمت المعالجة

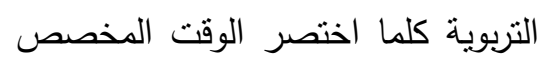

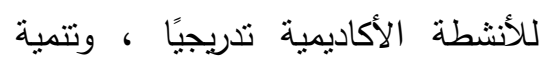
مهارات التفكير الابتكاري " الإبداعي " لإدياتيات ومهارات التفكير الناقد لدى الأطفال العاديين والأطفال المعاقين حركيًا وتتمنل الاطن في : " مهارات المرونة والطلاقة والأصالة اللغوية " . - وأكد كلٍ من ( إيمان كاثف وهشام

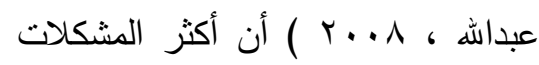
والتي تُعرض على المعالجين السلوكيين والمرتبطة بالقصور في مهارات الطفل

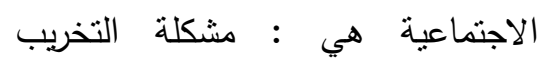

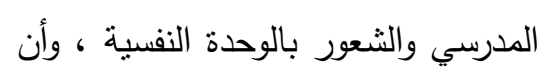
قضية المهارات الاجتماعية وتأثثرها في والئ وان
0) المستوى الاقتصادي الاجتماعي : فأطفال ذوي الإعاقة الحركية ذات الاتصنادي الطبقة الاجتماعية والاعلة الاقتصادية المرتفعة أفضل في التوافق والتكيف الطناعية الأحية من الأطفال ذوي الإعاقة الحركية ذات الطبقة الاجتماعية الاقتصادية الاعلية الحركية

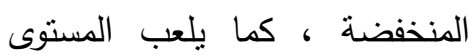

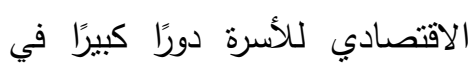

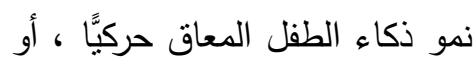
توقف نموه ـ النو 7) المدرسة : فالطفل المعاق حركيًّا في المدرسة يبدأ بالتحرر من الأسرة

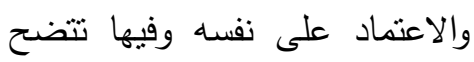
معالم شخصيته وعلاقاته بالمجتمع

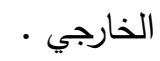
r-العوامل المتعقة بالظروف النفسية:

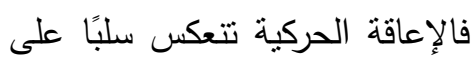
المعاق حركيًا في نموه الاجتماعي

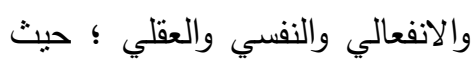
تؤدي الإعاقة الحركية إلى انخفاض ولفي ولفي صورة الجسم مما يترتب عليه انخفاض تقدير الذات ، والثعور

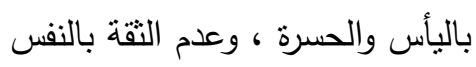

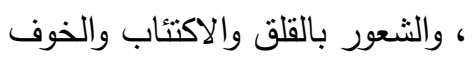
، كما تؤثر على مستوى تحصيله بلى والئل

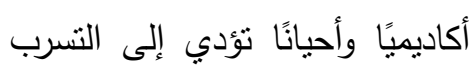

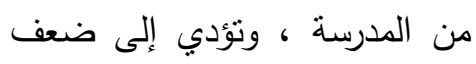
علاقاته مع الآخرين ، وعدم الرغبة في تكوين صداقات جديدة ، والميل إلى العزلة والانطواء ، و وتؤثر 
التكيف مع الإعاقات الحركية والتي يتحدى بها الثخص المعوق كل ما لإنهات يواجهه في حياته اليومية يُعد عاملًا بيئًا

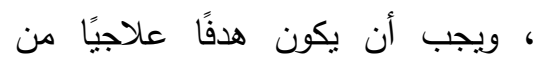

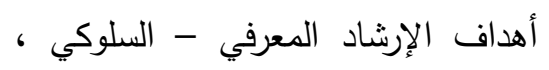
فعلى سبيل المثال : عندما بطلب الإني المعوق حركيًا المساعدة من الآخرين حول الأماكن التي لا يمكن الوصول

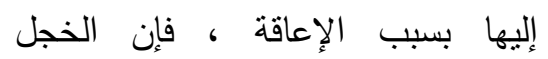

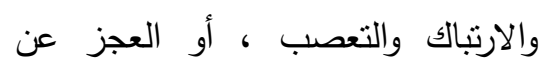
التعبير الاجتماعي ، ربما تتفاعل جميعًا مع الحاجة لمعالجة القضية الأساسية التي نواجهه ، وهي الإعاقة .

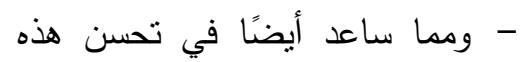

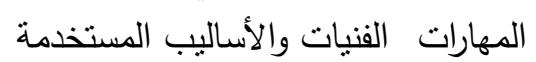
في البرنامج الإرشادي مثل : نشكيل

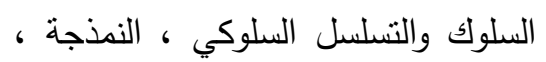

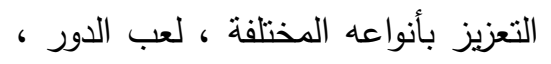

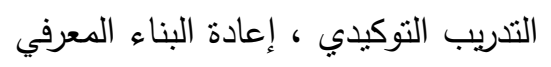

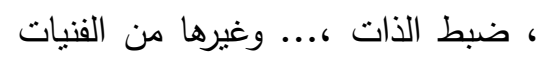
المستخدمة ، وكذلك استخدام الأنشطة المحببة للأطفال المعاقين حركيًّا والملتحقين بمدارس التعليم العام التي استخدمها الباحث أثناء تطبيقه للبرنامج في معظم جلساته سواء أكانت أنشطة ثقافية أو أنشطة اجتماعية أو أنشطة

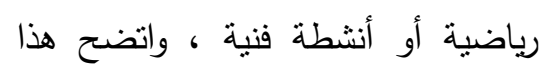
عندما تم حساب حجم الأثر والذي بلغ (19. · ) وهي قيمة مرتفعة ، ويوضح هذه النتائج شكل (1 ) ) التالي :
مشكلات السلوك من القضايا الجديرة بالبحث والتحليل . - بأكدت الدراسة الحالية أن النظريات السيكودينامية والنظريات المعرفية والنظريات البيولوجية والنظريات السلوكية وأصحاب الاتجاه السلوكي المعاصر ونظرية التعلم الاجتماعي ضرورية لتفسر التهاه تعلم مهارات السلوك التكيفي وخاصة نظرية التعلم الاجتماعي التي تقوم على أربعة محاور رئيسة ؛ هي : ( عملية الانتباه ، عملية الاحتفاظ ، عملية الأداء الحركي للسلوك ، عملية الدافعية ) وجميعها محاور تنعتمد على الأداءات العقلية والحسية ، وحتى يتمكن الطفل

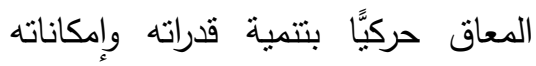
ومهاراته وإشباع حاجاته للمعايشة مع لئه متطلباته الحياتية اليومية وكذلك ليصل والت إلى المستوى المطلوب من الكفاءة العالية والنضج وذللك بمن هم في منل عمره . - وطبقًا للمنظور المعرفي - السلوكي ذكرا كلٌ من ( جمعة يوسف ومحمد لمدي

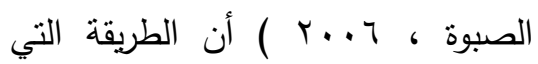
يتبعها المعوقين حركيًا في تفسير خبراتهم هي التي سوف تحدد مشاعرهم وما ، يصدر عنهم من أفعال وتصرفات وتؤدي ظروف الحياة والعوامل البيئية دورًا أساسيًا في حسم وتحديد طبيعة الفروض والمعارف والإدراكات المشوهة

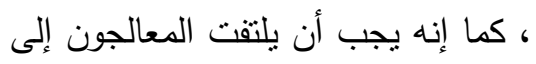

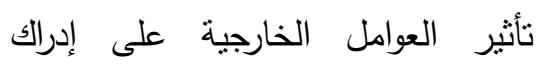
المعوقين لإعاقتهم الحركية ؛ وإن عملية 


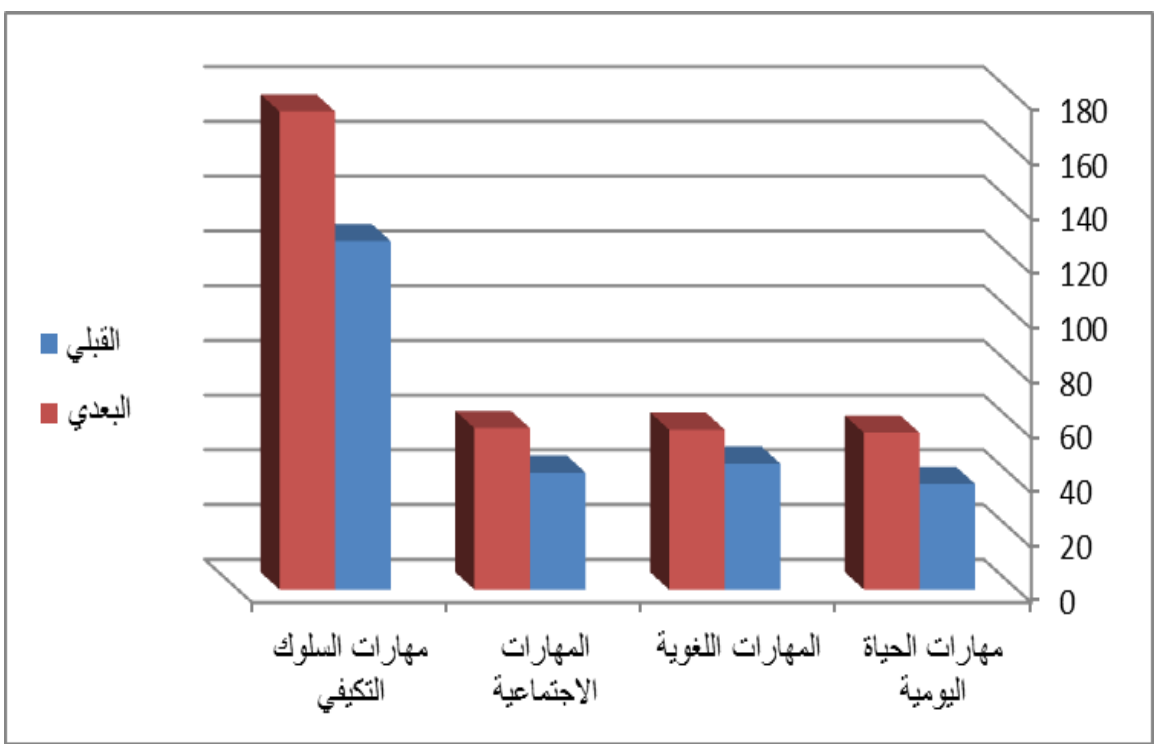

شكل (1) يوضح الفروق بين متوسطي القياس البعدي والقبلي لمقياس مهارات السلوك التكيفي للمجموعة التجريبية

لابارامتري يستخدم لمعرفة دلالة الفروق بين متوسطي رتب القياس القبلي والبعدي (عند صغر حجم العينة) أي دلالة الفروق بين مجموعتين مرتبطتين ويوضتح نتائج هذا الاختبار جدول ( 1 )

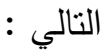

للتحقق من الفرض الثاني والذي ينص على :- " لا توجد فروق ذات دلالة إحصائية بين منوسطي رثب القياس البعدي والتتبعي لمقياس مهارات السلوك التكيفي للمجموعة التجريبية" ؛ استخدم الباحث اختبار ويلككسون (Wilcoxon) Signed Ranks Test

جدول(")

يبين قيمة (Z) لالالة الفروق بين متوسط رتب درجات أفراد المجموعة التجريبية في القياس البعدي والتتبعي لمقياس مهارات السلوك التكيفي (ن = V)

\begin{tabular}{|c|c|c|c|c|c|c|}
\hline مستوي & قيمة & مجموع & منوسط & العدد & المجموعة & المتغير \\
\hline \multirow{4}{*}{ غير دالة } & \multirow{4}{*}{$1 . \varepsilon 1 \leqslant$} & $\ldots$ & $\ldots$ & . & الرتب السالبة & \multirow{4}{*}{ هارات التكيفي } \\
\hline & & r... & 1.0. & r & الرتب الموجبة & \\
\hline & & & & 0 & الرنب المحايدة & \\
\hline & & & & $\mathrm{v}$ & المجموع & \\
\hline
\end{tabular}


1- التدريب المستمر على كل نشاط من الأنشطة إضافة إلى التكرار، لأن

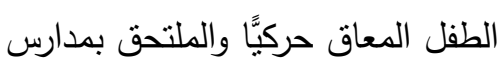
التعليم العام لا يستوعب الموقف

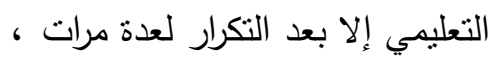

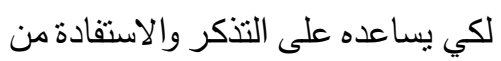

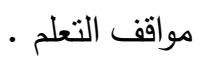
r- التدعيم حيث كان التدعيم يقدم عند نجاح الطفل المعاق حركيًا والملتحق بمدارس التعليم العام بأداء كل مهمة من المهام المطلوبة منه ، وهذا كان

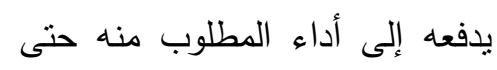
يحصل على التدعيم، واستخدم الباحث التدعيم بنوعيه المادي والمعنوي • r- الأنشطة والتثريبات التي استخدمت في البرنامج كانت من الأنشطة الدحبية التي تجذب الطفل المعاق المان حركيًا والملتحق بمدارس التعليم العام

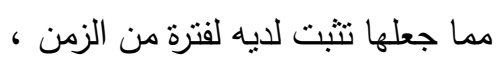
حيث إن الطفل المعاق حركيًا والملتحق بمدارس التعليم العام لم يكن

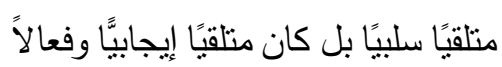
وكان بحاجة إلى إيقاظ تلك الدهارات

$$
\text { وتتشيطها وتوظيفها. }
$$

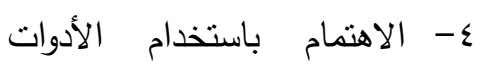
والوسائل المناسبة في البرنامج • باسني - ويوضح هذه النتائج شكل ( r )

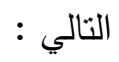

يتضح من الجدول ( 7 ) السابق أن قيمة ن ( Z )

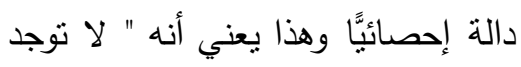
فروق ذات دلالة إحصائية بين متوسطات درجات أفراد المجموعة التجريبية في لين لين القياس التتبعي والبعدي في مستوى مهارات السلوك التكيفي " . - وبذلك أوضحت النتائج أنه " لا نوجد

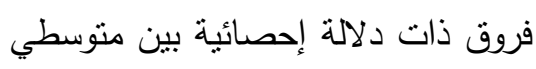
رتب القياس البعدي والتتبعي لمقياس

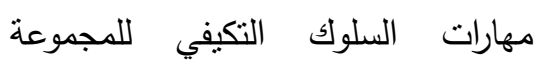
التجريبية " . مهارت - وهذا يعني أن البرنامج أسهم في تحسين أداء أفراد المجموعة التجريبية في مستوى مهارات السلوك التكيفي، وبقي هذا الأثر بعد نطبيق البرنامج

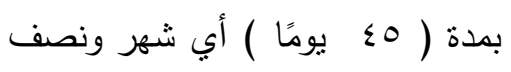
تقريبًا من تطبيق البرنامج ، مما يؤكد الدي

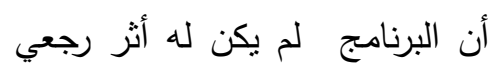
بسبب عامل الزمن، وأن البرنامج حقق لـ لرج رجي

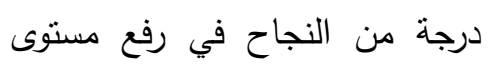
مهارات السلوك التكيفي استمر عبر الزمن - مهارت - ويفسر الباحث التوصل إلى النتيجة الحالية بما يلي : ليفنر 


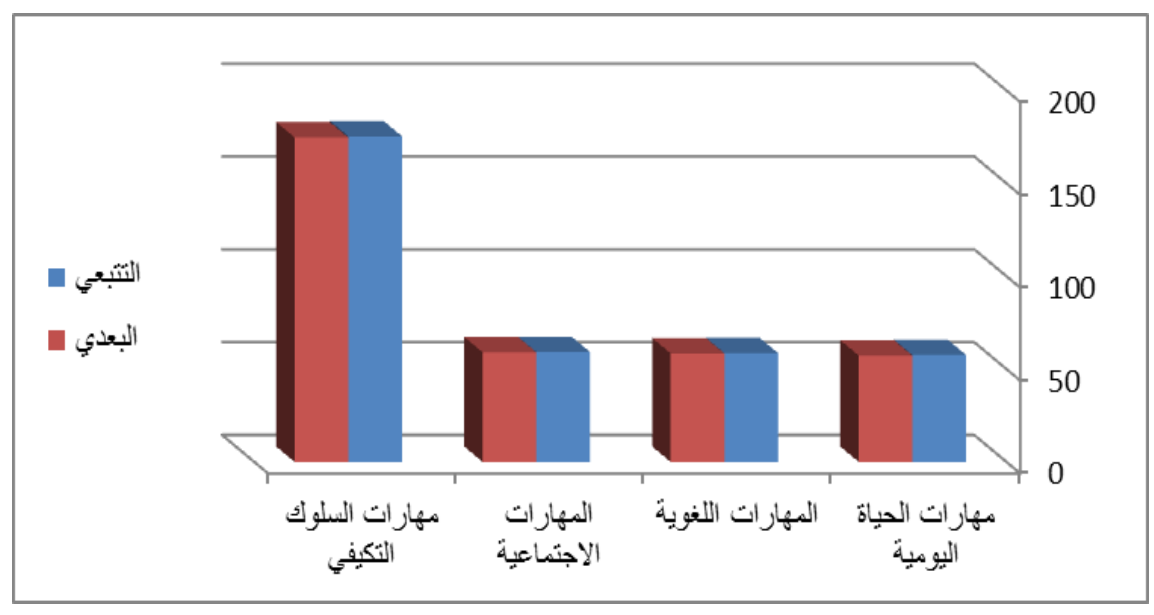

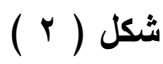

يوضح الفروق بين متوسطي القياس البعدي والتتبعي لمقياس مهارات السلوك التكيفي للمجموعة التجريبية

المعرفي السلوكي ، واتبع في تتمية مهارات السلوك التكيفي للأطفال المعاقين حركيًا الملتحقين بمدارس لعارس التعليم العام في الدراسة الحالية لاظهار الفاعلية في البرنامج الخطوات التالية :

1-تقديم نموذج للمفاهيم والمهارات الجديدة في كل جلسة إششادية على

حدة. . ل ح.

ץ-دعوة الطفل المعاق حركيًا والملتحق بالمدرسة للمشاركة في الأداء

$$
\text { وملاحظته . بالمدرنة }
$$

r-تثجيع الطفل المعاق حركيًا والملتحق بالمدرسة على الأداء بشكل مستقل وملاحظته .
- ومما سبق نجد أن البرنامج الإرشادي

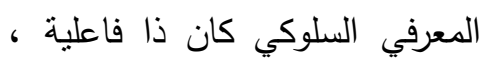
وحقق الغرض الذي وضع لأجله وهو تتمية مهارات السلوك التكيفي ، وكان السبب الرئيس الذي ساعد في نلك الأسس التي اعتمد عليها في بناء البرنامج والاستراتيجيات المستخدمة الخدئ

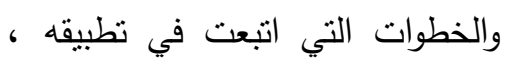

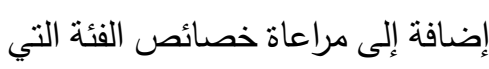
أُعد لأجلها، والتي لها خصائصها العقلية والجسمية والاجتماعية . .الخ التي تميزها عن غيرها وتحتاج إلى الى التئية استخدام الوسائل التي تتناسب معها.

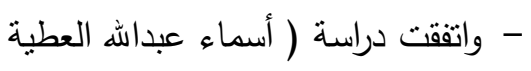

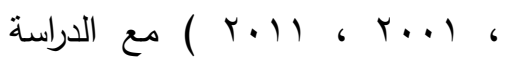

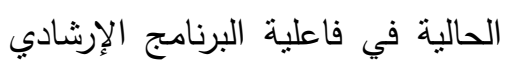


- وفي ذلك أوضح أيضًا ( إبراهيح

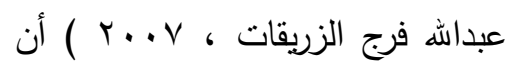
للإرشاد المعرفي السلوكي استخدمات

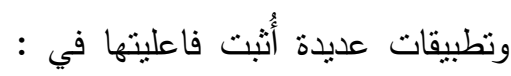
زيادة مستوى الاستقلالية وتحسين

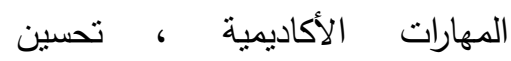
الدهارات السلوكية ، تعليم الثناعلات الاجتماعية ، فقد استخدم الإرشاد العاد المعرفي السلوكي في تعليم المهارات الإنتات

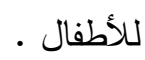

وتوضح الدراسة الحالية الوصف الإحصائي لكتغيرات الدراسة في جدول : التالي (V)
ع-تحديد جلسات إرشادية فردية في حالة غياب أحد الأطفال المعاقين حركيًا للتدريب على المهارات التي الإلي

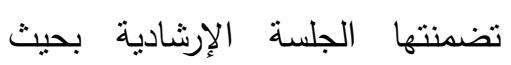
تُشضر قبل الجلسة الإرشادية بنصف الارثنادية بحت ساعة على الأقل . 0-تم توزيع مهارات البرنامج الإرشادي المعرفي السلوكي على فترات زمنية الرنات محددة ، وتحديد عدد جلسات التدريب

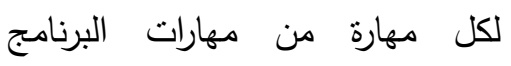

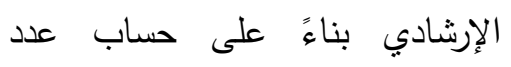
الجلسات الني استغرقت في التثريب على كل مهارة .

جدول (v)

الوصف الإحصائي لمتغيرات الدراسة في القياس القبلي والبعدي والتتبعي للمجموعة

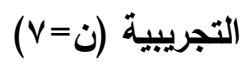

\begin{tabular}{|c|c|c|c|c|c|c|}
\hline \multicolumn{2}{|c|}{ التتبعي } & \multicolumn{2}{|c|}{ البعدي } & \multicolumn{2}{|c|}{ القبلي } & \multirow[b]{2}{*}{ الأبعاد } \\
\hline المتوسط & الانحراف & المتوسط & الانحراف & المتوسط & الالتحراف & \\
\hline $0 \mathrm{~V} .0 \mathrm{~V}$ & T.rV. & OV.Yq & r. $\leqslant 9 \wedge$ & r^.OV & $T . Y \leq 1$ & مهارات الحياة \\
\hline $01.0 \mathrm{~V}$ & .040 & $0 \wedge . \leqslant T$ &.$V A V$ & $\leq 7 .$. & $\varepsilon \ldots \leqslant 1$ & المهارات اللغوية \\
\hline $09.1 \leqslant$ & $.9 \ldots$ & $09 . .$. & .117 & $\varepsilon Y . V\}$ & r.7rA & الاجتماعية \\
\hline $1 V 0.19$ & r.VOr & $|V \leq . V|$ & r.. 9 & ITV.rq & $1 . .119$ & مهارات السلوك ككل \\
\hline
\end{tabular}

البعدي والتتبعي مما يؤكد ثنات التغير الحادث خلال القياسين البعدي والتتبعي في مقياس مهارات السلوك النكيفي

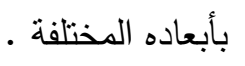

ويتضح من الجدول ( V ) السابق اختلاف المتوسطات بين القباس القبلي

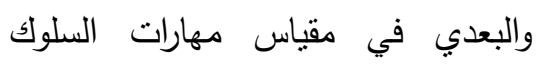
التكيفي بأبعاده المختلفة ، بينما هناك هناك تقارب بين المتوسطات بين القياس 


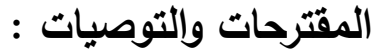

وفي ضوء ما توصلت إليه الدراسة من نتائج والتي أكدت فاعلية البرنامج والإطار النظري والدراسات السابقة يقترح الباحث تقديم بعض النوصيات التي تساعد في رفع مستوى الخدمات المقدمة إلى ذوي الإعاقة الحركية والملتحقين بمدارس التعليم العام ، وأيضًا رفع

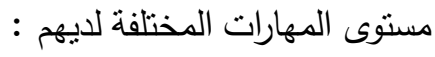

1-ضرورة التواصل بين الأسرة والمدرسة للتعرف إلى مشكلات ذوي الإعاقة الحركية الملتحقين بمدارس التعليم العام واحتياجاتهم وتقديم البرامج التدريبية والإرشادية للآباء والأمهات بهدف توجيههم إلى أفضل أساليب وطرق تعليم وتدريب ذوي الإعاقة الحركية

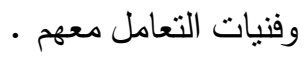

r- إعداد البرامج التدرييية والإرشادية متتوعة المثيرات التي تنتاسب مع قدرات ذوي الإعاقة الحركية الملتحقين بمدار التعليم العام وميولهم وتدفعهم للنجاح ·

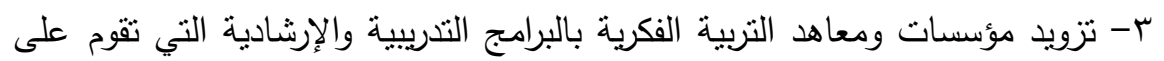
الأسس العلمية والتربوية في تدريب وتعليم ذوي الإعاقة الحركية وكذلك تدريب العاملين فيها على كيفية تطبيقها وتوظيفها بالطريقة التي تضمن الاستفادة منها. ع-تأهيل المدارس لاستيعاب ذوي الإعاقة الحركية بجانب التلاميذ العاديين ، وتدريب القائمين على العملية التعليمية لتعليم ذوي الإعاقة الحركية . ه-تزويد أماكن التعلم بالأجهزة التكنولوجية الحديثة وأدوات مساعدة لذوي الإعاقة الحركية في جميع المراحل التعليمية المختلفة . צ-إتاحة الفرصة لذوب الإعاقة الحركية الملتحقين بمدارس التعليم العام في الاشترالك بجميع الأنشطة سواء في الدرسة أو خارجها بما يتتاسب مع قدراتهم وميولهم لإظهار مواهبهم وإبداعاتهم من خلال البرامج والمسابقات المختلفة . . V-تحفيز ذوي الإعاقة الحركية المتميزين والمتفوقين علميًّا والموهوبين في كافة 
المجالات بدءًا من المدرسة الملتحق بها ـ

1- إنشاء كليات على مستوى الجامعات المصرية تختص وتهنم بعلوم وتأهيل ذوي الإعاقة بأنواعها المختلفة وخاصة الإعاقات الحركية المختلفة .

9- أن تتضمن خطط الوزارات برامج لذوي الإعاقة الحركية تتتاسب مع قدراتهم وإمكاناتهم ويتم التتسيق بين تلك الوزارات في تتفيذ هذه الخطط لإمكان دمج ذوي الإعاقة الحركية مع أقرانهم العاديين للاستقادة منهم في محاور التتمية بما يعود بالنفع والفائدة على

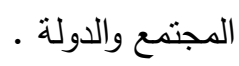

• 1-تخصيص بطاقة شخصية لذوي الإعاقة الحركية تتضمن مجانية تقديم

الخدمات بكافة مجالاتها ورعايتهم رعاية متكاملة .

قائمة المراجع

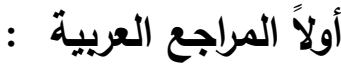

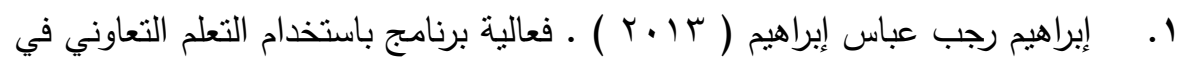

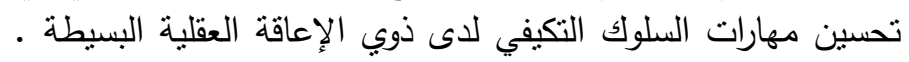

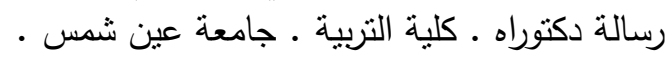

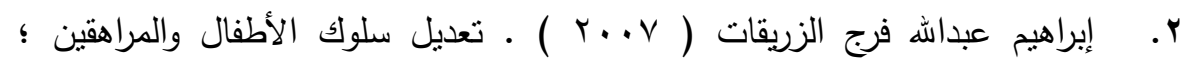

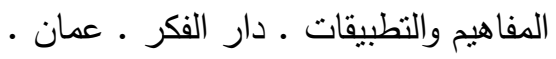

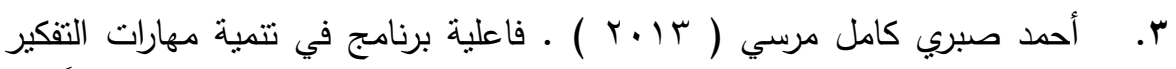

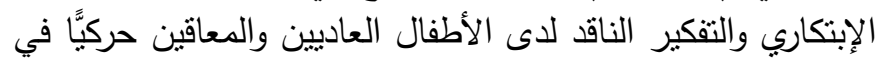

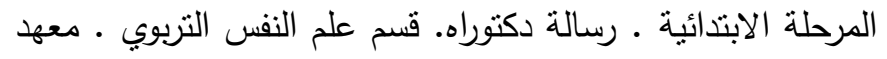
الدراسات التربوية ـ جامعة القاهية • ردالة دكورة

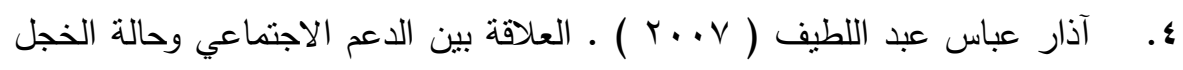

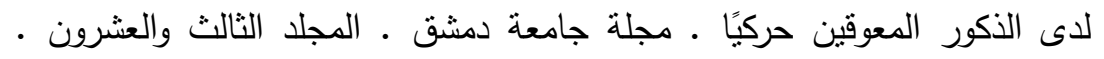
العدد الثاني • سوريا ل الثكورين 


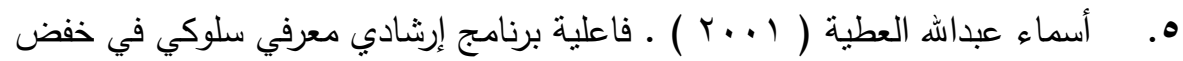

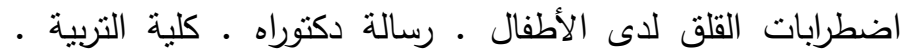

\section{جامعة عين شمس إن}

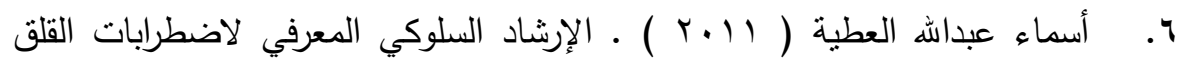

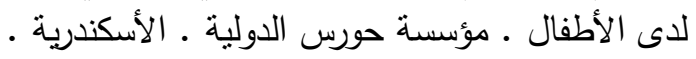

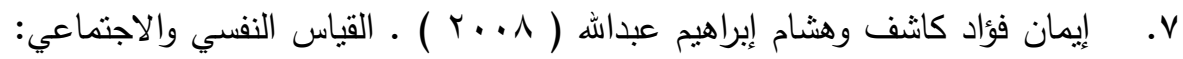

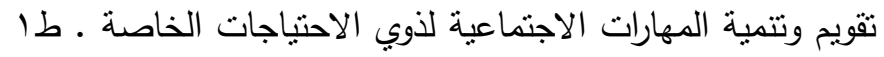

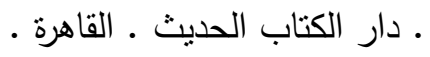

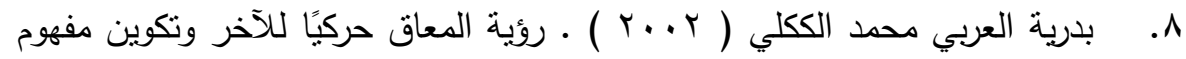

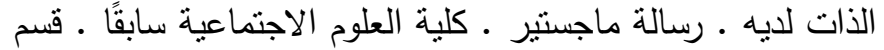

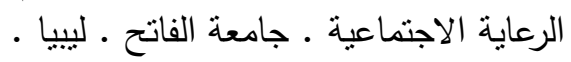

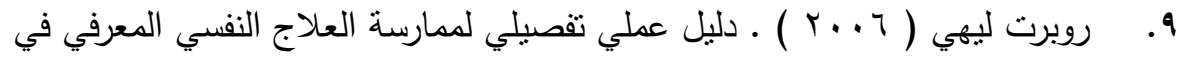

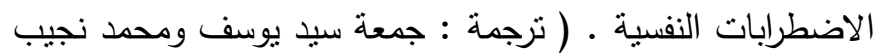

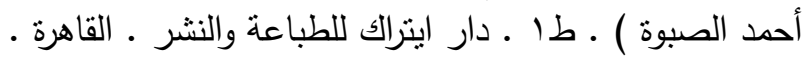

• 1 . سعاد كامل قرني ( 1 . . r ) . فعالية الإرشاد العقلاني الانفعالي السلوكي في خفض بعض مظاهر القلق الاجتماعي لدى عينة من المعاقين جسميَّا . رسالة

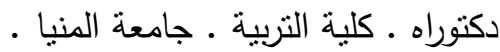

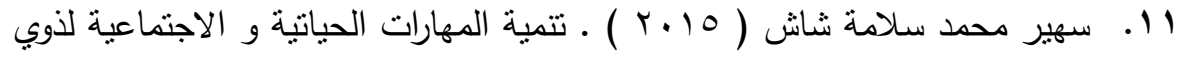

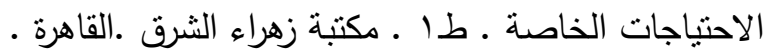

r ا . سهير محمود أمين عبداله ( ( . . ) ) . برنامج مقترح لتتمية التفكير الابتكاري لدى الأطفال المعوقين حركيًّا . مجلة القراءة والمعرفة ـ ـ عدد م(9) إصدار

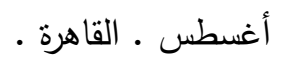

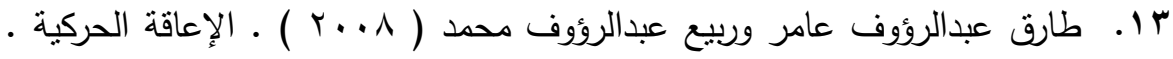

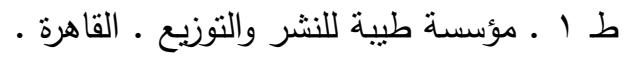

؛ 1 . عبداله سعد محمد الحسين ( ع . . ) . تقنيين مقياس السلوك التكيفي للجمعية

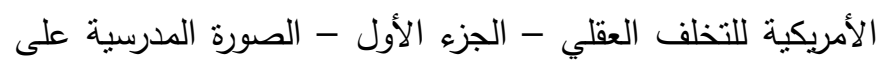


البيئة السعودية ـ رسالة دكتوراه ـ جامعة الخرطوم ـ الخرطوم •

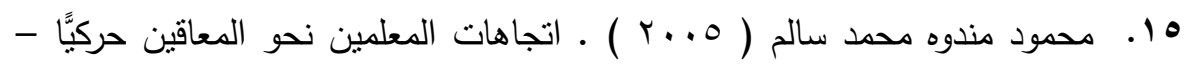

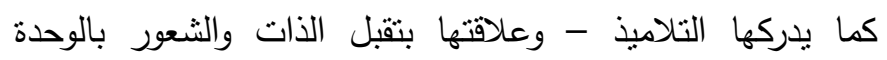

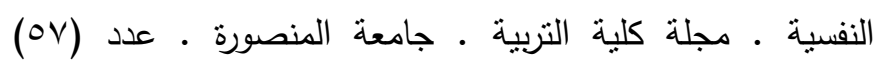

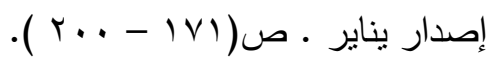

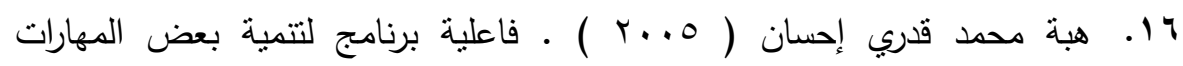

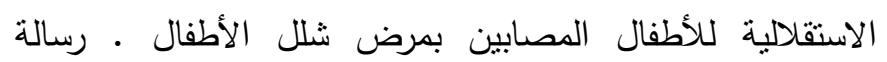

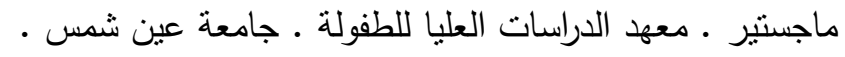

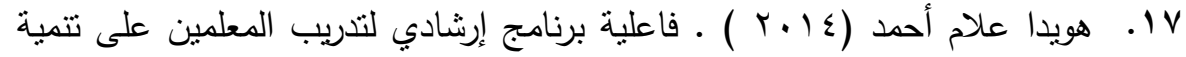

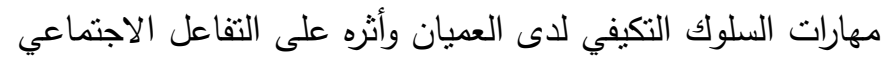

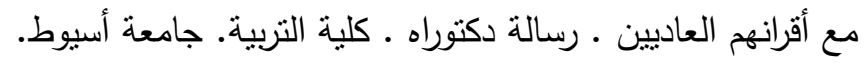

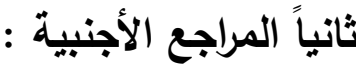

1^. Blake, T. J ., \& Jay, T. R,. ( ץ . ₹ ). " Physical Disability, Unemployment, and Mental Health ", Rehabilitation Psychology,V ( $₹$ १),p . $r \leqslant 1-r \leqslant q$

19. Harris , K . E., \& Ducharme , J . M,. ( $r \ldots r)$. Errorless embedding in the classroom. Enhancing the independent on task, Skills of children with behavior disorders, university of Toronto, Canada

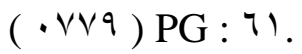

$r$.. Husain , Z.,\& Ahmad ,N . S,.. ( $\left.r_{\bullet} \cdot \bullet\right)$. Isolation Willingness of disabled Person to Integrate With Its Community in The Contextof Relationship after Disabled due to Accident , Procedia Social and Behavioral Sciences $, V(c) p . r \vee \varepsilon-r \wedge)$.

r. Koubek , E, $(\uparrow \cdots)$.Personal and Social Adjustment of Physically Handicapped Pubescent Psycho logia 
Dietata, J ro ( ) , p.rr-rq.

r. Paskiewicz , T, . ( $r \cdot q)$. A Comparison of adaptive behavior skills and IQ in three populations : children with learning disabilities, mental retardation, and autism . Unpublished Doctoral Dissertation, the Temple University Graduate Board .

rr. Sareen , J. ,\& Cox ,B. J.,\& Clara , I .,\& Asmundson,G ,. $(Y \ldots 0)$. " The relationship between anxiety disorders and physical disorders in the U.S. national comorbidity survey ", Depression And Anxiety, vol. ( ()$\left.^{\prime}\right)$, no. ( $\left.\varepsilon\right)$. 